\title{
Molecular and Biological Characterization of Distinct Strains of Jatropha mosaic virus from the Dominican Republic Reveal a Potential to Infect Crop Plants
}

\author{
Tomas A. Melgarejo, Tatsuya Kon, and Robert L. Gilbertson
}

First, second, and third authors: Department of Plant Pathology, University of California, Davis; first author: Departamento de Fitopatologia, Universidad Nacional Agraria La Molina, Lima, Peru; and second author: Plant Pathology Laboratory, Faculty of Agriculture, Iwate University, Morioka, Japan.

Accepted for publication 21 July 2014.

\begin{abstract}
Melgarejo, T. A., Kon, T., and Gilbertson, R. L. 2015. Molecular and biological characterization of distinct strains of Jatropha mosaic virus from the Dominican Republic reveal a potential to infect crop plants. Phytopathology 105:141-153.

In the Dominican Republic (DO), jatropha plants with yellow mosaic symptoms are commonly observed in and around fields of various crop plants. Complete nucleotide sequences of DNA-A and DNA-B components of four bipartite begomovirus isolates associated with symptomatic jatropha plants collected from three geographical locations in the DO were determined. Sequence comparisons revealed highest identities (91 to 92\%) with the DNA-A component of an isolate of Jatropha mosaic

isolates from the DO are strains of JMV. When introduced into jatropha seedlings by particle bombardment, the cloned components of the JMV strains from the DO induced stunting and yellow mosaic, indistinguishable from symptoms observed in the field, thereby fulfilling Koch's postulates for the disease. The JMV strains also induced disease symptoms in Nicotiana benthamiana, tobacco, and several cultivars of common bean from the Andean gene pool, including one locally grown in the DO. Asymmetry in the infectivity and symptomatology of pseudorecombinants provided further support for the strain designation of the JMV isolates from the DO. Thus, JMV in the DO is a complex of genetically distinct strains that have undergone local evolution and have the potential to cause disease in crop plants.
\end{abstract} virus (JMV) from Jamaica, indicating that the bipartite begomovirus
Plant viruses in the family Geminiviridae have circular singlestranded DNA genomes encapsidated within twinned (geminate) quasi-isometric virions $(34,35)$. Geminiviruses in the genus Begomovirus are transmitted in nature by the whitefly Bemisia tabaci, and this is the largest and most economically important genus $(31,35$, 70 ). The genome of begomoviruses is either bipartite, composed of two $\approx 2.6-\mathrm{kb}$ DNA components known as DNA-A and DNA-B; or monopartite, composed of a single DNA that is homologous to the DNA-A component of the bipartite begomoviruses $(7,70)$. Bipartite begomoviruses occur in the New World (NW) and Old World (OW) and do not require satellite DNAs for induction of typical disease symptoms (7). Although monopartite begomoviruses were initially found only in the OW, this situation has changed due to (i) the introduction of the OW monopartite Tomato yellow leaf curl virus (TYLCV) into the NW in the early 1990s (48) and (ii) the recent identification of an indigenous NW monopartite begomovirus causing leaf curl disease of tomato in Ecuador and Peru $(53,76)$. Most monopartite begomoviruses, with the exception of those that infect tomato, are associated with satellite DNAs that are either required for pathogenicity ( $\beta$ satellites) or have little or no effect on pathogenicity ( $\alpha$ satellites) $(7,58)$.

The DNA-A and DNA-B components of bipartite begomoviruses are completely different in sequence, with the exception

Corresponding author: R. L. Gilbertson; E-mail address: rlgilbertson@ucdavis.edu

* The $e$-Xtra logo stands for "electronic extra" and indicates that the online version contains three supplemental figures and three supplemental tables.

http://dx.doi.org/10.1094/PHYTO-05-14-0135-R

(c) 2015 The American Phytopathological Society of an $\approx 200$-nucleotide (nt) noncoding sequence referred to as the common region $(\mathrm{CR})$. The $\mathrm{CR}$ contains the viral origin of replication, including a stem-loop structure containing the invariant nanonucleotide TAATATT $\downarrow$ AC sequence $(3,31)$ and promoter sequences for transcription of the AC1 gene, which encodes the replication-associated protein (Rep), the only viral protein required for replication (31). Also contained within the CR are high-affinity Rep-binding sites with reiterated sequences or iterons that determine the specificity of Rep binding and serve to maintain the integrity of the bipartite genome $(31,34,35)$. The production of viable pseudorecombinants (PRs) by reassortment of infectious cloned components of bipartite begomoviruses is usually limited to isolates or strains of a particular virus or closely related species because of the highly specific nature of the interaction of Rep with the iterated sequences in the CR $(3,22)$. Thus, properties of PRs generated between bipartite begomoviruses can provide insight into their relationship $(10,12,17,26$, 27,30,37-40,42,67). If the PRs are highly infectious and symmetric (i.e., with symptoms and replication properties similar to those of the parental viruses), the viruses are isolates or variants of a species; if the PRs are infectious but asymmetric (i.e., having reduced symptom severity and replication in one or both combinations), the viruses are strains or closely related species; whereas, if the PRs are not infectious, the viruses are distinct species.

Several species of noncultivated plants (e.g., weeds), especially in the families Malvaceae, Euphorbiaceae, Fabaceae, and Solanaceae, are hosts of begomoviruses and often show striking golden yellow mosaic symptoms (55). In some cases, noncultivated plants can act as reservoirs of crop-infecting begomoviruses and serve as sources of primary inoculum $(2,4,5,25,73,75)$. Perhaps more importantly, these noncultivated plants serve as mixing 
vessels for the evolution and emergence of crop-infecting begomoviruses via mutation, recombination, and pseudorecombination $(25,49,54,68,79,84)$. Consistent with this notion, recent studies have suggested that begomovirus populations in noncultivated plants tend to be more variable than those of crop-infecting begomoviruses $(5,20,68,79,88)$. Thus, infection of noncultivated plants by combinations of genetically diverse DNA components increases the chances of the generation of variants with the potential to infect crop hosts and evolve into new crop-infecting begomoviruses $(44,73,81)$.

Jatropha (Jatropha spp., most likely Jatropha curcas) is a shrub-like weed of NW origin that is often found in disturbed environments, such as in and around agricultural fields in tropical and subtropical regions. Recently, there has been considerable interest in jatropha for its potential as a crop for biofuel production and soil restoration (e.g., in Africa and India) (1). In the Caribbean Basin, Jatropha spp. commonly show symptoms of begomovirus infection (e.g., golden or yellow mosaic in leaves). A bipartite begomovirus associated with these symptoms in J. gossypifolia in Jamaica has been named Jatropha mosaic virus (JMV) (72), and the complete sequence of an isolate of JMV from Jamaica (JMV [JM:Spanish Town:04], accession number KF723258) was recently deposited in GenBank. In the OW, where jatropha has been introduced, severe virus-like disease symptoms have been associated with begomovirus infection in India $(24,60)$ and Africa (45).

Here, we describe the characterization of the biological and molecular properties of bipartite begomovirus isolates associated with yellow mosaic disease of jatropha in the Dominican Republic (DO). We establish that these isolates are genetically distinct strains of JMV, and we fulfill Koch's postulates for the disease using infectious cloned DNA-A and DNA-B components. We further show that sequence divergence, involving mutation and recombination, and the asymmetric nature of PRs generated with the infectious cloned DNA components of these strains is consistent with a long history of local evolution of JMV in the DO. Finally, we show that JMV can infect the crop plants tobacco and common bean, making it a potential economic threat in the DO.

\section{MATERIALS AND METHODS}

Virus source, sample preparation, DNA extraction, and detection of begomovirus DNA. Leaves with yellow mosaic symptoms were collected from jatropha plants in three locations in the DO from 2010 to 2013 (Fig. 1). These locations were in the

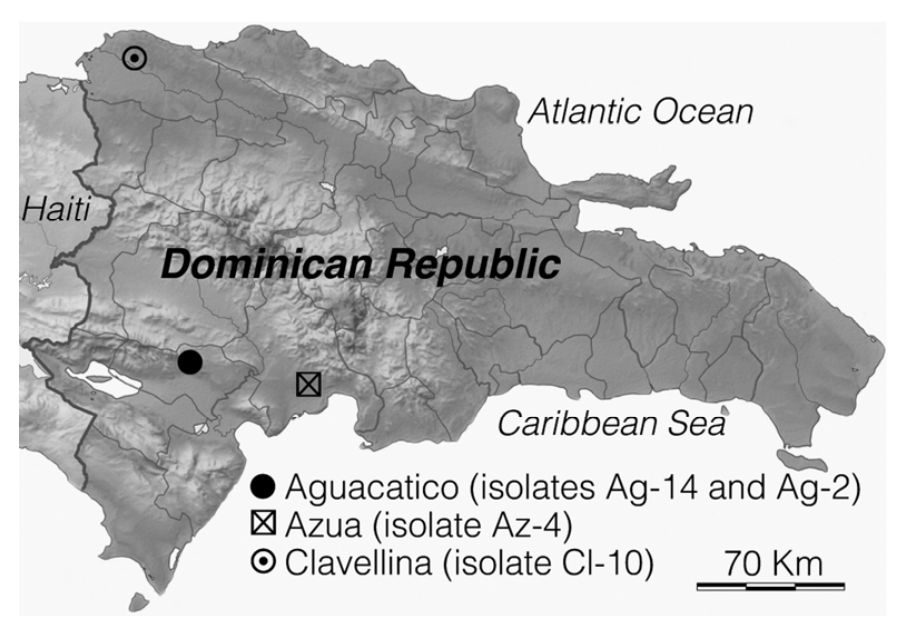

Fig. 1. Map of the Dominican Republic showing the locations where jatropha plants with yellow mosaic symptoms and begomovirus isolates were collected for this study. north (Clavellina), south (Azua), and southwest (Aguacatico), and were separated by mountains (the north from the south and southwest locations) or distances of $\approx 140 \mathrm{~km}$ (north from south and southwest locations) and $\approx 70 \mathrm{~km}$ (south from southwest locations). In the DO, sap was prepared from symptomatic leaves collected from single plants in Azua (in 2012) and Clavellina (in 2010) and two plants in Aguacatico (in 2010 and 2013). Sap was applied onto Agdia absorption strips (Agdia, Elkhart, IN), the absorbent pads were allowed to dry overnight, and then the absorption strips were transported to the University of California at Davis (UC Davis). Total genomic DNA was extracted from the dried plant sap on the absorbent pads according to the method of Dellaporta and colleagues (13). To detect begomovirus DNA-A and DNA-B components, polymerase chain reaction (PCR) with the degenerate primer pairs PAL1v1978/PAR1c496 and PCRc1/ PLB1v2040 (69), respectively, was performed. PCR-amplified DNA fragments were purified with the QIAquick gel extraction kit (Qiagen, Germantown, MD) and directly sequenced using the PAL1v1978 and PCRc1 primers for the DNA-A and DNA-B fragments, respectively, at the DNA Sequencing Facility, UC Davis.

Cloning of begomovirus DNA components. To obtain fulllength begomovirus clones, rolling circle amplification (RCA) with $\Phi-29$ DNA polymerase (TempliPhi; GE Healthcare, Piscataway, NJ) was used to generate circular double-stranded DNA replicons (43). The resulting RCA products were digested with various restriction enzymes to identify unique sites in each component for obtaining full-length clones (i.e., enzymes that generated linear $\approx 2.6-\mathrm{kb}$ fragments). Putative full-length DNA-A and DNA-B clones were then obtained by digesting RCA products with restriction enzymes that linearized the viral DNA components, gel purifying the resulting $\approx 2.6-\mathrm{kb}$ DNA fragment, and cloning the putative monomeric components into pGEM$11 \mathrm{Zf}(+)$ or pSL1180 (Promega Corp., Madison, WI) digested with the appropriate restriction enzyme. Recombinant plasmids were identified by restriction enzyme digestion and DNA sequence analyses.

Sequencing and phylogenetic analyses. DNA sequences were determined at the UC Davis DNA Sequencing Facility and analyzed using the Vector NTI advance software (Invitrogen, Carlsbad, CA). Pairwise nucleotide sequence alignments were performed with Muscle within the Species Demarcation Tool (SDT; v. 1.0) (59). SDT analysis with complete DNA-A sequences was then used to determine the relationship of the jatropha begomovirus isolates from the DO with the JMV isolate from Jamaica and the 44 most closely related begomoviruses revealed by results of a BLASTn search. Comparisons were also made with sequences of complete DNA-B component, the CR, and each gene of the jatropha begomovirus isolates from the DO, the JMV isolate from Jamaica, and the 14 most closely related begomoviruses.

For phylogenetic analyses, we included the jatropha begomovirus isolates from the DO, the JMV isolate from Jamaica, the 14 most closely related begomoviruses, and selected other begomoviruses representing the four major clades of NW bipartite begomoviruses: Abutilon mosaic virus (AbMV), Brazil, Squash leaf curl virus, and Bean golden yellow mosaic virus (BGYMV). Nucleotide sequence alignments of the complete sequences of DNA-A and DNA-B components were performed with the Muscle program in MEGA 5 (83), and the aligned nucleotide sequences were edited and exported as nexus files. Phylogenic trees were constructed by a Bayesian approach performed with MrBayes 3.2 (71). The best-fit model of nucleotide substitution was determined with the program jModelTest (65). The Bayesian analysis was carried out by running $2 \mathrm{M}$ generations and trees were sampled every 100th generation, resulting in 20,000 trees. After discarding the first $10 \%$ of samples as burn-in, the remaining 18,000 trees were used for calculating posterior probabilities 
in the consensus tree. Trees for the DNA-A and DNA-B sequences were generated in Treeview (62). The DNA-A sequence tree was rooted with the OW monopartite begomovirus TYLCV, whereas the DNA-B sequence tree was rooted with the DNA-B components of the OW bipartite begomoviruses Tomato leaf curl New Delhi virus and African cassava mosaic virus.

Evidence of non-tree-like evolution (indicative of recombination) was initially assessed with the Neighbor-Net method (9) implemented in the program SplitsTree4 v. 4.10 (41) and the data set that included the jatropha begomovirus isolates from the DO, the JMV isolate from Jamaica, and the 14 most closely related begomoviruses. Parental sequences and recombination break points were then determined using the Recombination Detection Program (RDP) v. 3.44 (51), with default settings and a Bonferroni-corrected $P$ value cutoff of 0.05 . Here, two data sets with the jatropha begomovirus isolates from the DO were used: one that included only Central American bipartite begomoviruses and another that included bipartite begomoviruses from the Americas. To minimize the probability of false-positive recombination events, only events detected by more than four of the seven methods implemented in RDP were considered to be valid (51). Similarity plot analysis was performed with SimPlot software 3.5.1 (50), using the Jukes-Cantor model and a window size and step size of 200 and $20 \mathrm{nt}$, respectively.

Production of multimeric clones and agroinoculation systems. To determine infectivity of the cloned begomovirus DNA-A and DNA-B components, multimeric clones were generated in the pCAMBIA1300 binary vector (33). For the DNA-A component of the isolate from Azua $(\mathrm{Az}-4)$, an $\approx 2.2-\mathrm{kb}$ EcoRI-HindIII fragment containing the $\mathrm{CR}$ was cloned into pCAMBIA1300 to generate the 0.8-mer pC-Az-4-A0.8. The fulllength monomer (HindIII fragment) was then cloned into the HindIII site of pC-Az-4-A0.8 to generate the 1.8 -mer pC-Az-4A1.8. For the DNA-B component of the Az-4 isolate, an $\approx 1.5-\mathrm{kb}$ NcoI-ClaI fragment containing the CR was cloned into pSL1180 to generate the 0.6-mer pSL-Az-4-B0.6. The full-length monomer (ClaI fragment) was then cloned into the ClaI site of pSL-Az-4B0.6 to generate the 1.6-mer pSL-Az-4-B1.6. This plasmid was then digested with EcoRI-HindIII and the resulting fragment (with the 1.6-mer) was cloned into pCAMBIA1300 to generate pC-Az-4-B1.6. For the DNA-A and DNA-B components of the isolate from Clavellina (Cl-10), a tandem dimer with the fulllength monomer (SacI fragment) was cloned into pCAMBIA1300 to generate the 2.0-mers $\mathrm{pC}-\mathrm{Cl}-10-\mathrm{A} 2.0$ and $\mathrm{pC}-\mathrm{Cl}-10-\mathrm{B} 2.0$, respectively. For the DNA-A component of the isolate from Aguacatico (Ag-14), an $\approx 2.3-\mathrm{kb}$ SacI-HindIII fragment containing the $\mathrm{CR}$ was cloned into pCAMBIA1300 to generate the 0.9-mer pC-Ag-14-A0.9. The full-length monomer ( $\mathrm{SacI}$ fragment) was then cloned into the SacI site of pC-Ag-14-A0.9 to generate the 1.9-mer pC-Ag-14-A1.9. For the DNA-B component of Ag-14, an $\approx 1.6-\mathrm{kb}$ SalI-SphI fragment containing the CR was cloned into pUC19 to generate the 0.6-mer pUC-Ag-14-B0.6. The full-length monomer ( $S p h \mathrm{I}$ fragment) was then cloned into the SphI site of pUC-Ag-14-B0.6 to generate the 1.6-mer pUC-Ag14-B1.6. This plasmid was then digested with EcoRI-HindIII, and the resulting fragment (with the 1.6-mer) was cloned into pCAMBIA1300 to generate pC-Ag-14-B1.6. Recombinant plasmids having the multimeric clones were identified by restriction enzyme digestion and transformed into competent Agrobacterium tumefaciens cells (strain $\mathrm{C} 58 \mathrm{C} 1$ ) with the freeze-thaw method (87).

Determination of infectivity and host range. Infectivity of the cloned DNA components was initially assessed by agroinoculation of Nicotiana benthamiana plants at the three- to fiveleaf stage (3 weeks old). Plants were inoculated with a mixture of A. tumefaciens cell suspensions (optical density at $600 \mathrm{~nm}=1.0$ ) carrying the DNA-A and DNA-B components of each isolate by needle puncture inoculation of the stem just beneath the shoot apex. Sap inoculation was performed as previously described (29). Sap was prepared from symptomatic leaf tissue from $N$. benthamiana plants agroinoculated with the multimeric cloned DNA components.

Infectivity of the cloned DNA components in jatropha seedlings was evaluated with three methods. Agroinoculation and sap inoculation were carried out as described above. Particle bombardment inoculation was performed with gold particles coated with the multimeric clones of the DNA-A and DNA-B components of each isolate and a PDS-1000 particle acceleration device (Du Pont, Wilmington, DE), as described by Paplomatas and colleagues (63).

Inoculated plants were maintained in a growth chamber and symptoms were monitored on a daily basis, with the final recording of disease incidence and symptoms at 18 to 21 days postinoculation (dpi). In selected symptomatic and all asymptomatic plants, the presence of DNA-A and DNA-B components in newly emerging (noninoculated) leaves was determined by PCR analysis with specific and degenerate primers (Supplemental Table 1).

Host range determination was performed by agroinoculation and sap inoculation of tobacco (N. tabacum 'Samsun'), N. glutinosa, Datura stramonium, tomato (Solanum lycopersicon 'Glamour'), pepper (Capsicum annuum 'Cayenne Long'), common bean (Phaseolus vulgaris 'Topcrop'), pumpkin (Cucurbita pepo 'Small Sugar'), Chenopodium quinoa, and C. amaranticolor plants. In addition, 15 common bean cultivars, representing the Andean and Middle American gene pools, were agroinoculated at the first internode (the point of attachment of primary leaves) by needle puncture (40).

Pseudorecombination experiments. Pseudorecombination experiments were performed by agroinoculating $N$. benthamiana and 'Jacomelo' common bean plants with mixtures of cell suspensions of $A$. tumefaciens strains carrying the multimeric clones of the DNA-A and DNA-B components of the Az-4, Cl-10, and Ag-14 isolates (40). Inoculated and control plants (inoculated with an $A$. tumefaciens strain with the empty vector) were maintained in a growth chamber, and symptoms were recorded 18 to 21 dpi.

Replication of DNA-A and DNA-B components was assessed in $N$. benthamiana leaves as described by Kon and colleagues (46). Total genomic DNA was extracted from infiltrated leaves $4 \mathrm{dpi}$, and $\approx 5 \mu \mathrm{g}$ of total genomic DNA was fractionated in $1.2 \%$ agarose gels in Tris-acetate-EDTA buffer and transferred to Hybond-N+ nylon membranes (Amersham Pharmacia, Piscataway, NJ). Blots were hybridized with a DNA-A-specific probe, which included fragments of the DNA-A components of Az-4 (nucleotides 196 to 608), Cl-10 (nucleotides 198 to 610), and Ag14 (nucleotides 202 to 614); or a DNA-B-specific probe, which included fragments of the DNA-B components of Az-4 (nucleotides 544 to 963), Cl-10 (nucleotides 1741 to 2119), and Ag-14 (nucleotides 605 to 1560). DNA probes were labeled with $\left[\alpha^{-32} \mathrm{P}\right]$ dCTP by nick translation. The amount of radioactivity of the DNA-A and DNA-B probes was standardized using a multipurpose scintillation counter (Beckman Coulter LS6500).

Quantification of the levels of the DNA-A and DNA-B components in infected plants was assessed by quantitative PCR (qPCR) in newly emerged leaves of $N$. benthamiana plants 14 days after agroinoculation. Component-specific primers were designed from a conserved region outside of the $\mathrm{CR}$, which included nucleotides 427 to 540 for DNA-A and nucleotides 1,784 to 1,885 for DNA-B. A primer pair designed to amplify an $\approx 100$-bp fragment of the $18 \mathrm{~S}$ ribosomal RNA gene was used as the standard internal control. The qPCR was conducted with $100 \mathrm{ng}$ of total genomic DNA in a $20-\mu \mathrm{l}$ reaction mix using the SsoFast EvaGreen Supermix kit (Bio-Rad, Richmond, CA) following manufacturer's instructions. For each sample, qPCR quantification was based on relative abundance as determined by 
threshold cycle value compared with the internal 18S control according to the method described by Schmittgen and Livak (77).

\section{RESULTS}

Detection, identification, and characterization of bipartite begomovirus isolates associated with jatropha yellow mosaic disease in the DO. PCR performed with DNA extracts prepared from leaf samples collected from jatropha plants with yellow mosaic symptoms in three locations in the DO (Azua [one sample], Clavellina [one sample], and Aguacatico [two samples]) (Fig. 1) and degenerate DNA-A and DNA-B primers generated 1.1- and $0.5-\mathrm{kb}$ fragments, respectively, consistent with infection with a bipartite begomovirus. Comparisons performed with the sequences of these PCR-amplified fragments revealed highest identities with sequences of DNA-A and DNA-B components of bipartite begomoviruses from the NW (data not shown). These results indicated that the jatropha plants with yellow mosaic symptoms from these three locations in the DO were infected with one or more NW bipartite begomoviruses.

Full-length clones of the DNA-A and DNA-B components of the begomovirus isolates from these four samples were obtained by linearizing RCA products and cloning the resulting $\approx 2.6-\mathrm{kb}$ fragments. The cloned DNA-A and DNA-B components from each plant sample were considered to represent a distinct bipartite begomovirus isolate: Az-4 from Azua, Cl-10 from Clavellina, and Ag-14 and Ag-2 from Aguacatico. The complete nucleotide sequences of the cloned full-length DNA-A and DNA-B components of each isolate were determined. The DNA-A and DNA-B components of the Az-4 isolate were 2,604 nt (accession number $\mathrm{KJ} 174332$ ) and 2,595 nt (accession number KJ174336), respectively; those of the $\mathrm{Cl}-10$ isolate were 2,606 nt (accession number KJ174331) and 2,576 nt (accession number KJ174335), respectively; and those of the Ag-14 and Ag-2 isolates were 2,609 nt (accession number KJ174330) and 2,602 nt (accession number KJ174334) and 2,611 nt (accession number KJ174333) and 2,586 nt (accession number KJ174337), respectively. The DNA-A component of each isolate has a genome organization typical of NW bipartite begomoviruses; that is, a single gene on the viral-sense strand (AV1) that encodes the capsid protein $(\mathrm{CP})$ and four genes on the complementary-sense strand (AC1, AC2, $\mathrm{AC} 3$, and $\mathrm{AC} 4$ ) that encode the Rep, the transcription activator protein (TrAP), the replication enhancer (REn), and the AC4 proteins, respectively. Furthermore, the $\mathrm{CP}$ amino acid sequence of these isolates possessed the N-terminus motif PWRPmAGt (lowercase indicates variable amino acid residues), which is found exclusively in NW begomoviruses (36). The DNA-B component of each isolate has a single gene on the viral-sense strand (BV1) that encodes the nuclear shuttle protein (NSP), and one on the complementary-sense strand $(\mathrm{BC} 1)$ that encodes the movement protein (MP).

The SDT analysis revealed that the complete DNA-A sequences of the Az-4, Cl-10, Ag-14, and Ag-2 isolates from jatropha in the DO were 91.6, 90.6, 92.3, and 91.8\% identical, respectively, to that of the isolate of JMV from Jamaica. Pairwise comparisons of the complete DNA-A sequences of the isolates from the DO revealed 91 to $94 \%$ identity, whereas identities for the DNA-B component sequences of the isolates from the DO and the JMV isolate from Jamaica were slightly lower ( 88 to $91 \%$ ). Furthermore, comparisons of the nucleotide and amino acid sequences of individual genes of the jatropha begomovirus isolates from the DO and the isolate of JMV from Jamaica revealed a wide range ( 80 to $99 \%$ ) of identities, some of which were lower than those expected for isolates of a bipartite begomovirus species (Supplemental Table 2). The AV1, AC3, and BC1 genes were highly conserved $(\geq 92 \%$ nucleotide and $\geq 94 \%$ amino acid sequence identities), whereas identities for the $\mathrm{AC} 1, \mathrm{AC} 4$, and BV1 genes were considerably lower. For example, the Ag-14 isolate had AC1/Rep, AC4, and BV1/NSP nucleotide and amino acid identities of 91 and 92,90 and 77 , and 91 and $91 \%$, respectively, with the JMV isolate from Jamaica; 88 and 87,90 and 79 , and 87 and $89 \%$, respectively, with the Cl-10 isolate; 90 and 91, 93 and 84, and 90 and 92\%, respectively, with the Az-4 isolate; and 89 and 90, 92 and 82, and 90 and 91\%, respectively, with the Ag-2 isolate. Similar results were obtained in comparisons made with sequences of the other isolates, with the exception of the Az-4 and Ag-2 isolates, which had higher overall identities (e.g., AC1/Rep, AC4, and BV1/NSP nucleotide and amino acid identities of 95 and 96, 98 and 94, and 94 and 95\%, respectively) (Supplemental Tables 2 and 3). Taken together, these results indicate that the jatropha begomovirus isolates $\mathrm{Cl}-10$ and Ag-14 from the DO, as well as the JMV isolate from Jamaica, are strains of JMV, whereas isolates Az-4 and Ag-2 are variants of a different strain (Az-4).

The DNA-A and DNA-B components of each of the four JMV isolates from the DO and the isolate from Jamaica share a CR of $\approx 200$ nt, with $>96 \%$ nucleotide sequence identity (data not shown). This is well above the $90 \%$ threshold for DNA-A and DNA-B components of an isolate of a bipartite begomovirus species (18). The CR sequences have the characteristic geminivirus stem-loop structure, with the conserved nanonucleotide sequence TAATATT $\downarrow$ AC, Rep reiterated binding sites, and the AC1 TATA box (35). However, comparisons made among the CR sequences of these five JMV isolates revealed considerable genetic diversity. First, the DNA-A component CR sequence identities ranged from 78 to $93 \%$, whereas those of the DNA-B components ranged from 80 to $91 \%$. These values are lower than those for isolates of a begomovirus, which are typically $>95 \%$, providing further evidence that these isolates represent distinct strains of JMV. Second, some of the isolates have different Rep reiterated binding sites and inverted repeat sequences. The Az-4 and Ag-2 isolates have the same sequences, whereas those of the Ag-14 and Cl-10 have different sequences (Fig. 2A). Similarly, these isolates also have different Rep iteron-related domains (IRDs), and these correspond to the iterons of their cognate DNA$\mathrm{A}$ and DNA-B components. Interestingly, the JMV isolate from Jamaica has a different reiterated sequence (GGGGGAATGGGGG), inverted repeat (CCCCC), and IRD (GSFSIK) (Fig. 2A). Together, these results revealed a relatively high level of sequence diversity in the CR and IRD sequences, which is consistent with the $\mathrm{Cl}-10$ and Ag-14 isolates and the isolate JMV from Jamaica representing distinct JMV strains and isolates Az-4 and Ag-2 representing variants of a different JMV strain (Az-4 strain).

Comparisons of the complete nucleotide sequences of the DNA-A and DNA-B components of the JMV strains or variants from the DO and Jamaica and those of other begomoviruses revealed highest identities with DNA-A and DNA-B components of NW bipartite begomoviruses from Latin America (Supplemental Table 2). For example, for the Ag-14 strain, the highest DNA-A component identities were 88 and $86 \%$ with two tobaccoinfecting begomoviruses from Cuba: Tobacco mottle leaf curl virus (TbMoLCV) and Tobacco leaf curl Cuba virus (TbLCuCV), respectively. In the case of the DNA-B component, the highest identities were 78 and $76 \%$ with sequences of Wissadula golden mosaic virus (WGMV) from Jamaica and Tomato yellow distortion leaf curl virus from Cuba, respectively (note that there is no DNA-B sequence for TbMoLCV or TbLCuCV in GenBank). Similar results were obtained in comparisons made with the CR and individual gene sequences (Supplemental Table 3).

Phylogenetic analyses. In the phylogenetic analysis performed with the complete DNA-A component sequences, the JMV strains or variants were placed together in a distinct clade along with TbMoLCV from Cuba. The JMV Az-4 and Ag-2 isolates were more closely related, consistent with these being variants of a JMV strain. Interestingly, in this analysis, the Ag-14 strain from the DO was most closely related to the JMV isolate from Jamaica. 
The clade with the JMV strains or variants was part of the AbMV clade, which includes bipartite begomoviruses that infect cultivated and noncultivated hosts from Colombia, Cuba, Jamaica, Mexico, and Venezuela (Fig. 2B). In the phylogenetic analysis performed with the complete DNA-B component sequences, the JMV strains or variants were also placed in a distinct clade. The $\mathrm{Az}-4$ and Ag-2 isolates were again most closely related, whereas the JMV isolate from Jamaica was more distantly related to the isolates from the DO (Supplemental Figure 1). As with the DNAA tree, the JMV clade was part of the AbMV clade. Taken together with results of the sequence comparisons, these results indicate that JMV is a distinct bipartite begomovirus species that is most closely related to NW bipartite begomoviruses from Latin America.

Recombination analysis. The Neighbor-Net analysis revealed a non-tree-like evolutionary relationship among JMV strains or variants (Supplemental Figure 2). The results indicated cycles within the neighbor networks generated between JMV strains or variants and the most closely related begomoviruses (bipartite begomoviruses from Latin America), which is suggestive of recombination. The RDP recombination analysis identified a recombination event in the $\mathrm{Cl}-10$ strain with $P$ values of $1.9 \times 10^{-8}$, $2.6 \times 10^{-7}, 1.2 \times 10^{-10}, 1.9 \times 10^{-3}, 8.5 \times 10^{-6}$, and $3.3 \times 10^{-8}$ for the RDP, Geneconv, Bootscan, MaxChi, Chimaera, and SiScan

A

JMV [JM:Spanish Town:04] A TCCCCCGATTGCTCCTCGCTCAAAACTCTCTATGAA. TTGGGGGAATGGGGGAACATT TATAC MPRKGSFSIKAKN

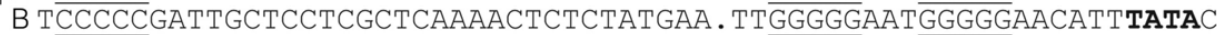

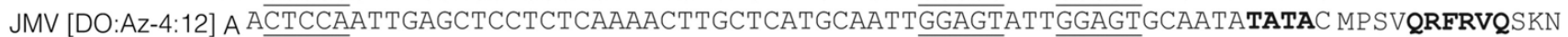
B A $\overline{C T C C A} A T T G A G C T C C T C T C A A A A C T T G C T C A T G T A A T T \overline{G G A G T A T T G G A G T G C A A T A T A T A C}$

JMV [DO:Ag-2:13] A A $\overline{C T C C A A T T G A G C T C C T C T C A A A A C T T G C T C A T G C A A T T G G A G T A T T ~ G G A G T A A C T T A T A T A C ~ M P S V N K F R V Q S K N ~}$ B ACTCCAATTGAGCTCCTCTCAAAACTTGCTCATGCAATTGGAGTATTGGAGTAACTTATATAC

JMV [DO:Cl-10:10] A TACCCCAATTGAGCTCCTCTCAAACTTACTCATTCAATTGGGGTAATGGGGGACAATATATAC MPSVRRFKVSAKN В TACCCCAATTGAGCTCCTCTCAAACTTACTCATTCAATTGGGGTAATGGGGGACAATATATAC

JMV [DO:Ag-14:10] A TACCCCGATTCGGCTCTCTCAACTTCTGTGCTATGAATTGGGGTAATGGAGAC. AATATATAC MPS IKRFKVSAKN B TACCCCGATTCGGCTCTCTCAACTTCTGTGCTATGAATT

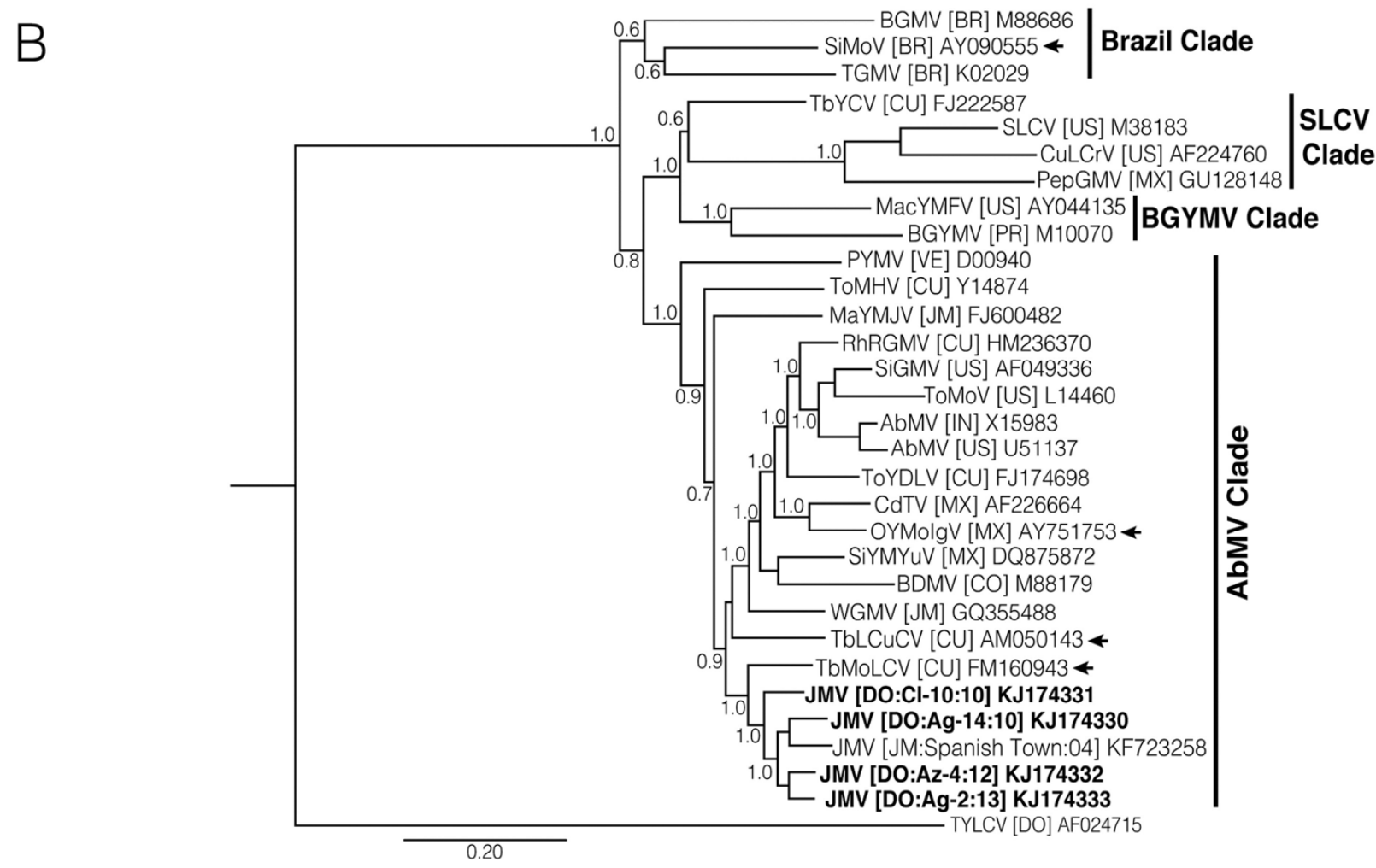

Fig. 2. Characterization of Jatropha mosaic virus (JMV) isolates from three geographical locations in the Dominican Republic (DO). A, Alignment of a portion of the common region (CR) nucleotide sequence including the replication-associated protein (Rep) reiterated binding site. The nucleotide sequence and orientation of the Rep binding-site iterons and inverted repeats are underlined and shown with arrows, respectively. The TATA box of the AC1 (Rep) gene is indicated in bold letters. The Rep iteron-related domain (IRD) in the $\mathrm{N}$ terminus of the Rep protein is shown to the right of the CR alignment, with the potential amino acids involved in iteron recognition indicated in bold letters. B, Bayesian phylogenetic consensus tree constructed with the complete nucleotide sequences of the DNAA component and showing the relationship among JMV isolates from the DO (shown in bold letters), the most closely related bipartite New World (NW) begomoviruses (identified by a BLASTn analysis), and selected begomoviruses representing the Abutilon mosaic virus (AbMV), Brazil, Bean golden yellow mosaic virus (BGYMV), and Squash leaf curl virus (SLCV) clades. The DNA-B components of some of the NW begomoviruses (indicated by arrows) have not been identified or characterized. Branch strengths were evaluated by Bayesian posterior probabilities. Note that the Brazil clade is supported by a low posterior probability value (0.6). The monopartite begomovirus Tomato yellow leaf curl virus (TYLCV) was used to root the tree. The length of horizontal branches indicates the rate of substitution per nucleotide. Sequences were obtained from GenBank and their respective accession numbers are indicated. 
recombination methods, respectively. The break points identified for this event were located within the AC1 and AC4 genes (nucleotides 1,901 to 2,250). The SimPlot analysis confirmed the recombination event in the DNA-A component of the Cl-10 strain, and results of sequence comparisons that indicated the majority of sequence divergence in the JMV DNA-A sequences is in the $\mathrm{AC} 1$ and $\mathrm{AC} 4$ genes and the CR (Fig. 3; Supplemental Table 3). These findings are also consistent with previous studies that identified this region as a hot spot of recombination (39, 47,61). Finally, the RDP analysis indicated that the major parent of the Cl-10 strain was Rhynchosia rugose golden mosaic virus (RhRGMV) and the minor parent was Tobacco yellow crinkle virus (TbYCV), bipartite begomoviruses from Cuba. RhRGMV infects the leguminous weed Rhynchosia minima (19), whereas TbYCV infects crop hosts such as tobacco and pepper (21). Similarly, an intraspecific RDP analysis of the JMV strains or variants also revealed evidence of recombination in this region, further suggesting a role for recombination in the evolution of JMV (data not shown).

Infectivity, symptomatology, and host range of JMV strains from the DO. Most of the N. benthamiana plants (92 to 100\%) agroinoculated with the full-length cloned DNA-A and DNA-B components of the JMV strains Az-4, Cl-10, and Ag-14 developed stunting and severe crumpling, deformation, and yellow mosaic symptoms in leaves by 6 dpi (Fig. 4; Table 1). The presence of begomovirus DNA-A and DNA-B components in newly emerged leaves of representative symptomatic plants agroinoculated with each strain was established by PCR with strain-specific and degenerate DNA-A and DNA-B primers, respectively (Table 1). These results established the infectivity of the cloned DNA-A and DNA-B components of these JMV strains and supported the results of CR comparisons, indicating that these are cognate DNA components. All three JMV strains were sap transmitted to $N$. benthamiana plants and induced symptoms indistinguishable from those in agroinoculated plants. Interestingly, the efficiency of sap transmission varied among strains; for example, the rate of sap transmission for the Az-4 strain was $<50 \%$, whereas rates for the Cl-10 and Ag-14 strains were 100\%.

Jatropha plants agroinoculated with the cloned DNA-A and DNA-B components of the $\mathrm{Cl}-10$ and $\mathrm{Ag}-14$ strains did not develop symptoms or become infected based on the failure to detect viral DNA in newly emerged leaves by PCR. Similarly, jatropha plants inoculated with sap prepared from leaves of $N$. benthamiana plants infected with the $\mathrm{Cl}-10$ strain did not become

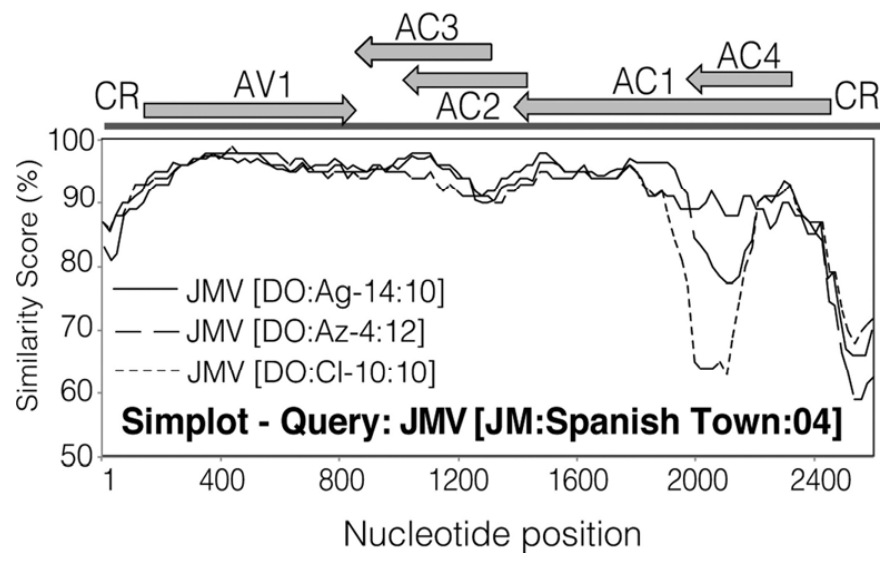

Fig. 3. Similarity plot analysis of total nucleotide sequences of the DNA-A component of three strains of Jatropha mosaic virus (JMV) from the Dominican Republic (DO) and the isolate from Jamaica JMV (JM:Spanish Town:04). Each line represents a comparison between the sequence of the three strains of JMV from the DO and the reference (Query) sequence (JMV isolate from Jamaica). Each point represents the percent identity within a sliding window of $200 \mathrm{bp}$ moving in increments of $20 \mathrm{bp}$. Horizontal arrows indicate the position of the genes encoded by the DNA-A component. infected (Table 1). However, jatropha seedlings inoculated with the cloned multimeric DNA-A and DNA-B components of each JMV strain by particle bombardment developed stunting, crumpling, and yellow mosaic symptoms in newly emerged leaves by 14 days postbombardment (Fig. 4; Table 1). Furthermore, the DNA-A and DNA-B components of the inoculated strains were detected in newly emerged leaves of symptomatic plants by PCR with strain-specific and degenerate primers, respectively. Together, these results established that the cloned DNA-A and DNA-B components of the three JMV strains from the DO were infectious and induced yellow mosaic symptoms in jatropha, thereby fulfilling Koch's postulates for jatropha yellow mosaic disease.

The host range of the JMV strains Az-4, Cl-10, and Ag-14 was investigated by agroinoculation and sap inoculation of a range of plant species. In contrast to $N$. benthamiana, very low rates of infectivity were obtained in sap-inoculated tobacco and common bean plants, and no infections were detected in other host species inoculated with sap (Table 1). Thus, sap transmission was not an efficient method for assessing the host range of JMV. Agroinoculation is a very efficient method to assess infectivity of infectious geminivirus clones in certain hosts, including members of the families Fabaceae, Cucurbitaceae, and Solanaceae (85). Therefore, the agroinoculation results will be emphasized. In addition to $N$. benthamiana, disease symptoms developed in Topcrop common bean at $10 \mathrm{dpi}$ and in Samsun tobacco at $6 \mathrm{dpi}$, whereas a symptomless infection was detected in $N$. glutinosa. In common bean, all three JMV strains induced similar symptoms, including stunting, leaf crumpling, and epinasty (Fig. 5A). In contrast, the JMV strains showed differential pathogenicity in tobacco. The Cl-10 strain induced stunting, crumpling, and deformation of leaves, whereas strains Az-4 and Ag-14 induced less stunting and moderate crumpling and yellow mosaic symptoms in leaves (Fig. 5B). The JMV strains did not infect $C$. amaranticolor, C. quinoa, D. stramonium, Glamour tomato, Small Sugar pumpkin, and Cayenne Long pepper plants.

Common bean is an important food crop in the DO, and golden mosaic disease caused by the bipartite begomovirus BGYMV is an important constraint on production (28). To further investigate the pathogenicity of JMV in common bean and to assess the potential of the virus to affect common bean production in the $\mathrm{DO}$, germplasm representing the two major common bean gene pools (Andean and Middle American) as well as two Andean cultivars commonly grown in the DO, Jacomelo and 'San Juanero', were agroinoculated with the three JMV strains. None of the Middle American genotypes developed symptoms or became infected (Table 2). In contrast, five of eight Andean genotypes became infected and developed symptoms. The highest infection rate was observed for the 'Jatu Rong' (71 to 86\%), whereas infection rates were 21 to $53 \%$ for 'Alubia', 'Bellagio', Topcrop, and 'Tortolas Corrientes' (Table 2). For the cultivars grown in the DO, all three JMV strains infected and induced symptoms in Jacomelo, whereas none of the strains infected or caused symptoms in San Juanero. Furthermore, in Jacomelo, the Az-4 and Ag-14 strains had higher rates of infectivity (87 and $76 \%$, respectively) than the $\mathrm{Cl}-10$ strain $(40 \%)$. The symptoms induced by the JMV strains in the susceptible common bean genotypes were similar to those previously described in Topcrop, and were indistinguishable among strains. Thus, these JMV strains have differential pathogenicity in common bean, infecting and causing symptoms only in some Andean genotypes. However, the virus has the potential to cause economic loss in the DO, where at least one susceptible cultivar is grown commercially.

Pseudorecombination experiments with infectious cloned DNAs of JMV strains from the DO. Relationships among bipartite begomoviruses can be assessed based upon the properties of PRs. Thus, the relationship among the JMV strains from the DO was investigated by determining the infectivity and symp- 
tomatology of PRs formed between the infectious cloned DNA components of the Ag-14, Az-4, and Cl-10 strains in N. benthamiana and common bean plants. The properties of the PRs varied depending on the combination of components and host plant. In $N$. benthamiana, PRs formed with the DNA-A component of the $\mathrm{Cl}-10$ strain and the DNA-B components of the Az-4 strain $(\mathrm{Cl}-$ $10-\mathrm{A} / \mathrm{Az}-4-\mathrm{B})$ or the $\mathrm{Ag}-14-\mathrm{B}$ strain (Cl-10-A/Ag-14-B) were highly infectious (100\% infectivity) and induced severe symptoms, and both DNA components were detected in newly emerged leaves of all plants tested (Table 3). In contrast, PRs formed with the DNA-A component of the Az-4 strain and the DNA-B components of the Cl-10 strain (Az-4-A/Cl-10-B) or the Ag-14-B strain (Az-4-A/Ag-14-B) did not develop symptoms, although DNA-A-only infections were detected in all plants tested. PRs formed with the DNA-A component of the Ag-14 strain and the DNA-B components of the Cl-10 strain (Ag-14$\mathrm{A} / \mathrm{Cl}-10-\mathrm{B})$ or the $\mathrm{Az}-4$ strain (Ag-14-A/Az-4-B) were highly infectious (100\% infectivity) and induced mild and delayed symptoms, and both DNA components were detected in newly emerged leaves of all plants tested (Table 3; Fig. 6).

In common bean, only the $\mathrm{Cl}-10-\mathrm{A} / \mathrm{Ag}-14-\mathrm{B}$ PR induced disease symptoms, and both DNA components were detected in newly emerged leaves of all plants tested. The symptoms induced by this PR were similar to those induced by the cognate DNA-A and DNA-B components of the $\mathrm{Cl}-10$ and Ag-14 strains. Interestingly, although the $\mathrm{Cl}-10-\mathrm{A} / \mathrm{Az}-4-\mathrm{B} \mathrm{PR}$ induced severe symptoms in $N$. benthamiana, this PR did not induce symptoms in common bean, although DNA-A-only infections were detected in $60 \%$ of inoculated plants (Table 3). DNA-A-only infections were also detected in plants inoculated with the Ag-14-A/Az-4-B and Ag-14-A/Cl-10-B PRs but not in plants inoculated with the Az-4-A/Cl-10-B and Az-4-A/Ag-14-B PRs (Table 3).

Results of leaf disc replication and $\mathrm{qPCR}$ assays revealed that the infectivity and pathogenicity of the JMV PRs is associated

TABLE 1. Infectivity, host range, and symptomatology of three Jatropha mosaic virus (JMV) strains (Az-4, Cl-10, and Ag-14) from the Dominican Republic ${ }^{a}$

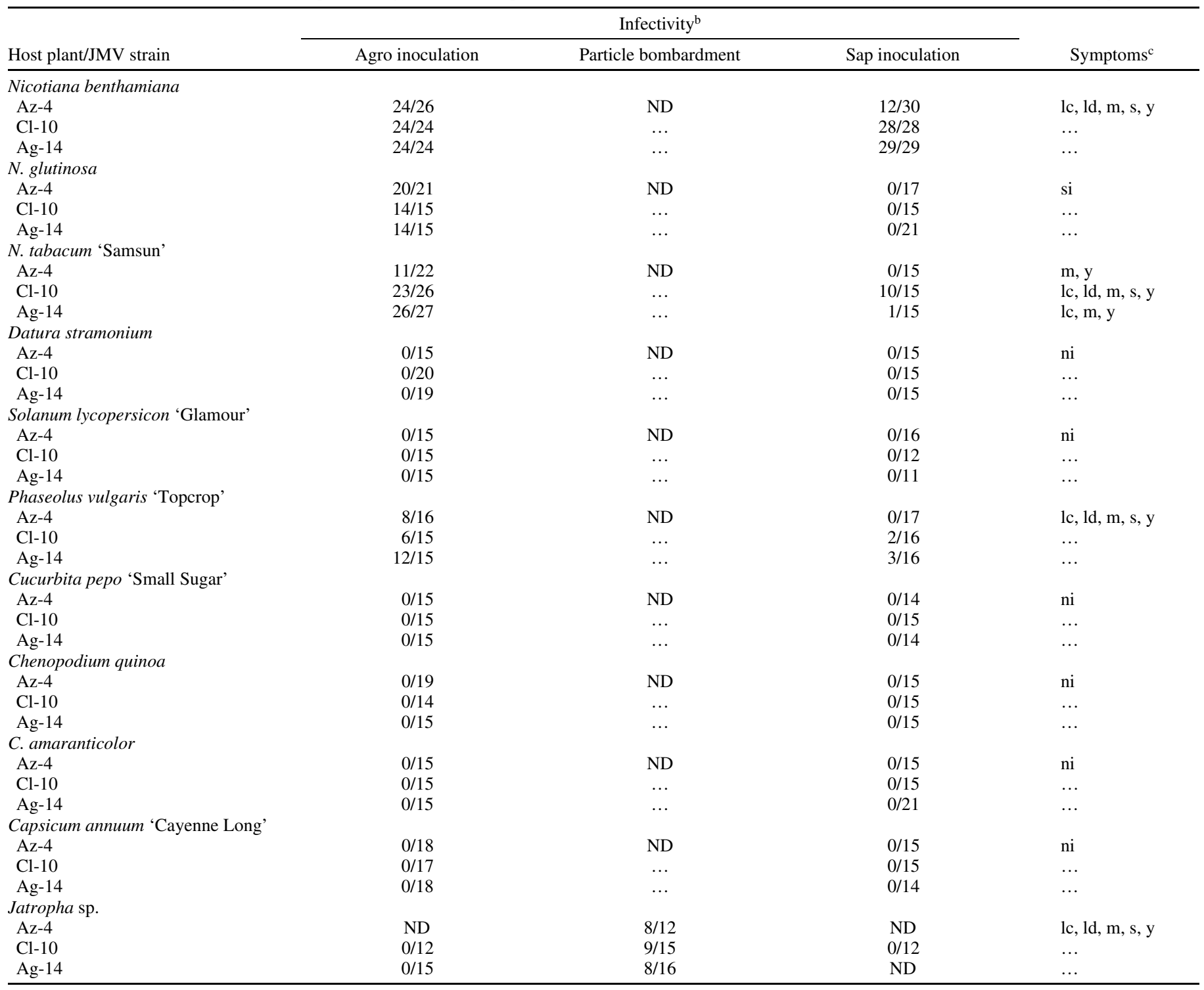

${ }^{a}$ Infectious cloned DNA-A and DNA-B components of the JMV strains were delivered by agroinoculation, except for jatropha plants, which were inoculated by particle bombardment. For sap-transmission, sap was prepared from Nicotiana benthamiana plants infected with the appropriate strain following agroinoculation.

${ }^{\mathrm{b}}$ Infectivity (number of infected plants/number inoculated) was determined 18 to 21 days after inoculation based on symptom development and detection of viral DNA components by polymerase chain reaction with strain-specific (DNA-A) and degenerate (DNA-B) primer pairs. Results represent data from three independent experiments; $\mathrm{ND}=$ not determined.

${ }^{\mathrm{c}}$ Symptom abbreviations: $\mathrm{lc}=$ leaf crumpling, $\mathrm{ld}=$ leaf deformation, $\mathrm{m}=$ mosaic, $\mathrm{ni}=$ no infection (i.e. $=$ no symptoms and no viral DNA detected in newly emerged leaves), $\mathrm{s}=$ stunting, $\mathrm{si}=$ symptomless infection, and $\mathrm{y}=$ yellowing. Symptoms were identical in each host unless otherwise noted. 
with the capacity of (i) the DNA-A component to replicate the DNA-B component and (ii) both components to move, long distance, in infected plants. Thus, for the Cl-10-A/Ag-14-B and Cl-10-A/Az-4-B PRs, which were highly pathogenic in N. benthamiana, the Cl-10 DNA-A component replicated the DNA-B components of the Ag-14 and Az-4 strains to levels that were similar to those observed for the cognate components of these JMV strains (Fig. 6G). Furthermore, both components of these PRs were detected at high levels in newly emerged leaves of infected plants (Supplemental Figure 3). In contrast, the Az-4 DNA-A component did not replicate the DNA-B components of strains Cl-10 or Ag-14 (Fig. 6G), nor were either of the DNA-B components of these PRs detected in newly emerged leaves of inoculated plants. These results are fully consistent with the lack of infectivity of the PRs with the Az-4 DNA-A component. The Ag-14-A/Az-4-B and Ag-14-A/Cl-10-B PRs, which induced a mild symptom phenotype in $N$. benthamiana plants, had relatively low levels of DNA-B replication in the leaf disc assay (Fig. 6G), whereas higher DNA-B levels were detected in the qPCR assay. This difference may relate to the fact that the replication assay was performed in leaf discs at $4 \mathrm{dpi}$, whereas the qPCR assay was performed in newly emerged leaves of inoculated plants at $14 \mathrm{dpi}$. It is also important to note that both components of these PRs were detected by PCR in newly emerged leaves of $N$. benthamiana plants (Table 3), consistent with the capacity of both components to move long distance in this host.

Further insight into the biological properties of the PRs came from an analysis of the iteron and IRD sequences of the DNA-A and DNA-B components. Geminivirus iterons have been grouped on the basis of similarities in the $\mathrm{GGN}_{1} \mathrm{~N}_{2} \mathrm{~N}_{3}$ core and the IRD amino acids of the Rep protein, which were numbered in respect to the invariant amino acid $\mathrm{F}$ as a reference point: $\mathrm{X}_{-\mathrm{n}} \ldots \mathrm{X}_{-2} \mathrm{X}_{-1} \mathrm{~F}$
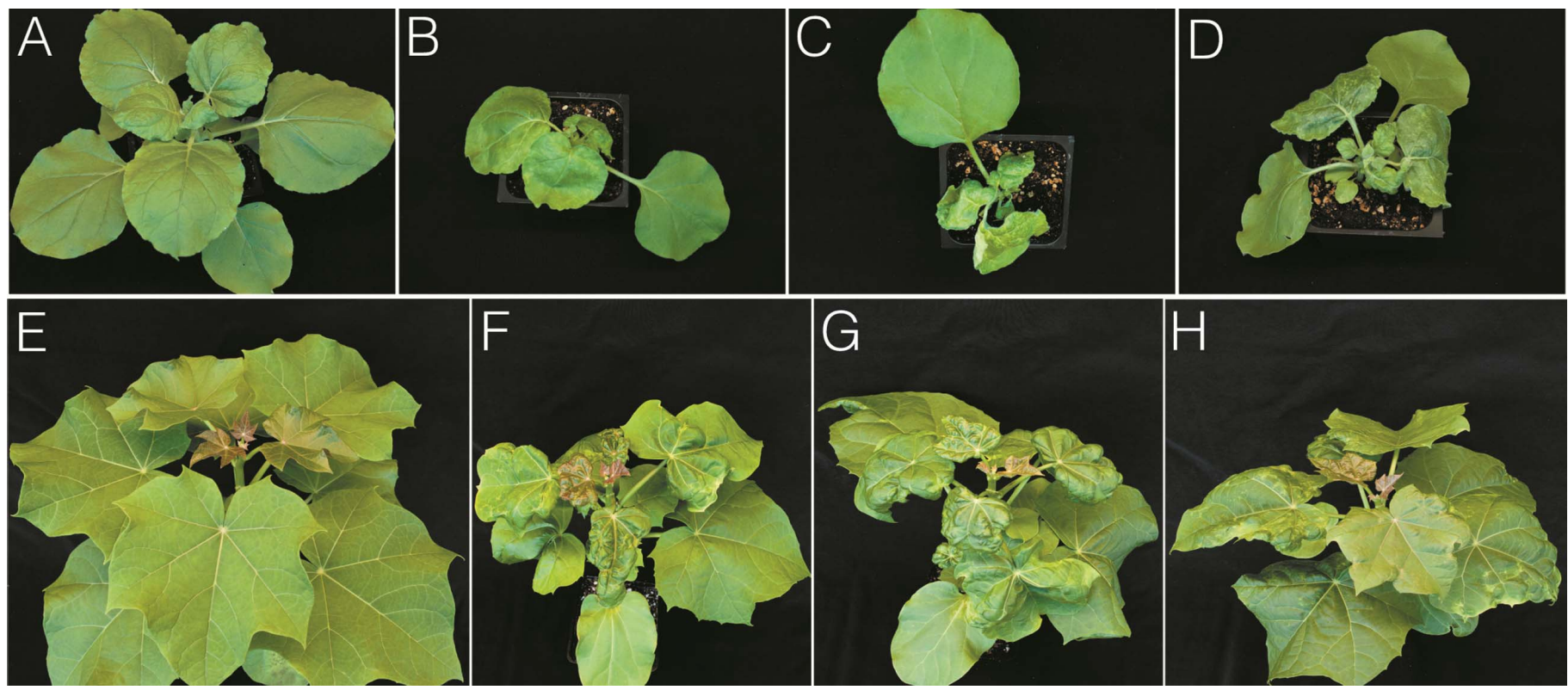

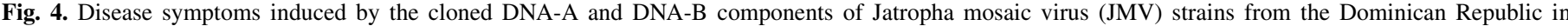

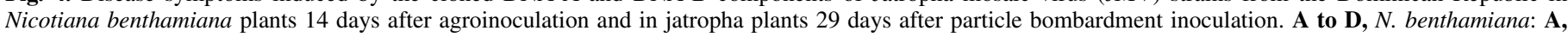

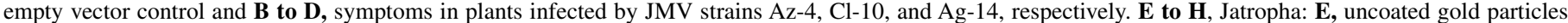
alone control and $\mathbf{F}$ to $\mathbf{H}$, symptoms in plants infected by JMV strains Az-4, Cl-10, and Ag-14, respectively.

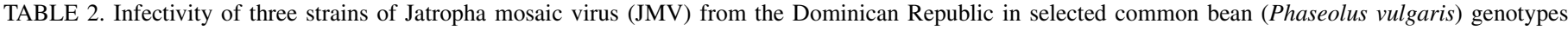
following agroinoculation

\begin{tabular}{|c|c|c|c|c|c|}
\hline \multirow[b]{2}{*}{ Genotype } & \multirow[b]{2}{*}{ Gene pool ${ }^{\mathrm{a}}$} & \multirow[b]{2}{*}{ Race } & \multicolumn{3}{|c|}{ JMV strain ${ }^{b}$} \\
\hline & & & $\mathrm{Az}-4$ & Cl-10 & Ag-14 \\
\hline Jatu Rong & $\mathrm{A}$ & Nueva Granada & $10 / 13$ & $10 / 14$ & $12 / 14$ \\
\hline Topcrop & A & Unknown & $8 / 13$ & $6 / 15$ & $4 / 13$ \\
\hline Tortolas corriente & A & Chile & $8 / 12$ & $8 / 15$ & $3 / 13$ \\
\hline Alubia & A & Nueva Granada & $6 / 15$ & $2 / 13$ & $6 / 12$ \\
\hline Bellagio & A & Unknown & $3 / 13$ & $0 / 12$ & $3 / 14$ \\
\hline Alubia cerillos & A & Nueva Granada & $0 / 13$ & $0 / 12$ & $0 / 11$ \\
\hline Coscorron corrientes & A & Chile & $0 / 9$ & $0 / 10$ & $0 / 11$ \\
\hline RedHawk & A & Unknown & $0 / 13$ & $0 / 12$ & $0 / 14$ \\
\hline Jacomelo & A & Unknown & $13 / 15$ & $6 / 15$ & $13 / 17$ \\
\hline Sanjuanero & A & Unknown & $0 / 13$ & $0 / 14$ & $0 / 13$ \\
\hline Aurora & M & Mesoamerica & $0 / 13$ & $0 / 13$ & $0 / 14$ \\
\hline Carioca & M & Mesoamerica & $0 / 14$ & $0 / 13$ & $0 / 14$ \\
\hline Dor 500 & M & Mesoamerica & $0 / 14$ & $0 / 14$ & $0 / 12$ \\
\hline Pinto Othello & M & Durango & $0 / 28$ & $0 / 26$ & $0 / 24$ \\
\hline Porrillo sintetico & M & Mesoamerica & $0 / 14$ & $0 / 13$ & $0 / 12$ \\
\hline $\mathrm{T}-39$ & $\mathrm{M}$ & Mesoamerica & $0 / 14$ & $0 / 14$ & $0 / 12$ \\
\hline Zacatecano & M & Durango & $0 / 14$ & $0 / 13$ & $0 / 13$ \\
\hline
\end{tabular}

a Gene pool abbreviations: $\mathrm{M}=$ Middle American and $\mathrm{A}=$ Andean.

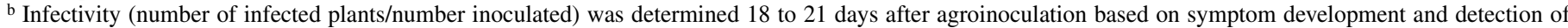
viral DNA components by polymerase chain reaction with strain-specific (DNA-A) and degenerate (DNA-B) primer pairs. Results represent data from three independent experiments. 
$\mathrm{X}_{1} \mathrm{X}_{2} \mathrm{X}_{3}$, where $\mathrm{X}_{-\mathrm{n}}$ is the first amino acid of the Rep protein $(3,67)$. The $N_{1}$ nucleotide in the iteron correlates with the $X_{3}$ amino acid of the IRD, and the $\mathrm{N}_{2}$ nucleotide correlates with $\mathrm{X}_{1}$ amino acid. Furthermore, for geminiviruses having GGGGG or GGTGG iterons, the $\mathrm{N}_{3}$ nucleotide correlates with the $\mathrm{X}_{-2}$ amino acid of the IRD (3). Based on these "rules", the inability of the JMV Az-4 DNA-A component to form viable PRs with the Cl-10 and Ag-14 DNA-B components may be explained by the specific interaction of the $X_{3}$ amino acid of the Az-4 Rep-IRD (Q) with the iteron $\mathrm{N}_{1}$ nucleotide (A), which occurs only for the cognate Az-4 components (Fig. 2A). The amino acid $\mathrm{R}$ or $\mathrm{K}$ in the position $\mathrm{X}_{-2}$ of the $\mathrm{Cl}-10$ or Ag-14 Rep-IRD, respectively, interacts specifically with the nucleotide in the $\mathrm{N}_{3}$ position, which is invariant in the first iteron of the JMV strains (T) but is highly variable in the second iteron ( $\mathrm{T}, \mathrm{G}$, or $\mathrm{A})$. Thus, the mild symptoms and lower levels of DNA-B replication of the Ag-14A/Az-4-B and Ag-14-A/Cl-10-B PRs could be explained by less efficient interaction of the IRD and the $\mathrm{N}_{3}$ nucleotide in the second iteron. The positively charged $\mathrm{R}$ and $\mathrm{K}$ amino acid residues are exposed on the surface and play important roles in protein stability by forming electrostatic interactions $(6,66)$. Furthermore, the guanidinium group of the $\mathrm{R}$ residue allows interactions in three possible directions, which allows this residue to form a larger number of electrostatic interactions compared with $K$ (15). Therefore, the $\mathrm{R}$ residue in the position $\mathrm{X}_{-2}$ of the $\mathrm{Cl}-10$ IRD may provide more flexibility to interact with divergent
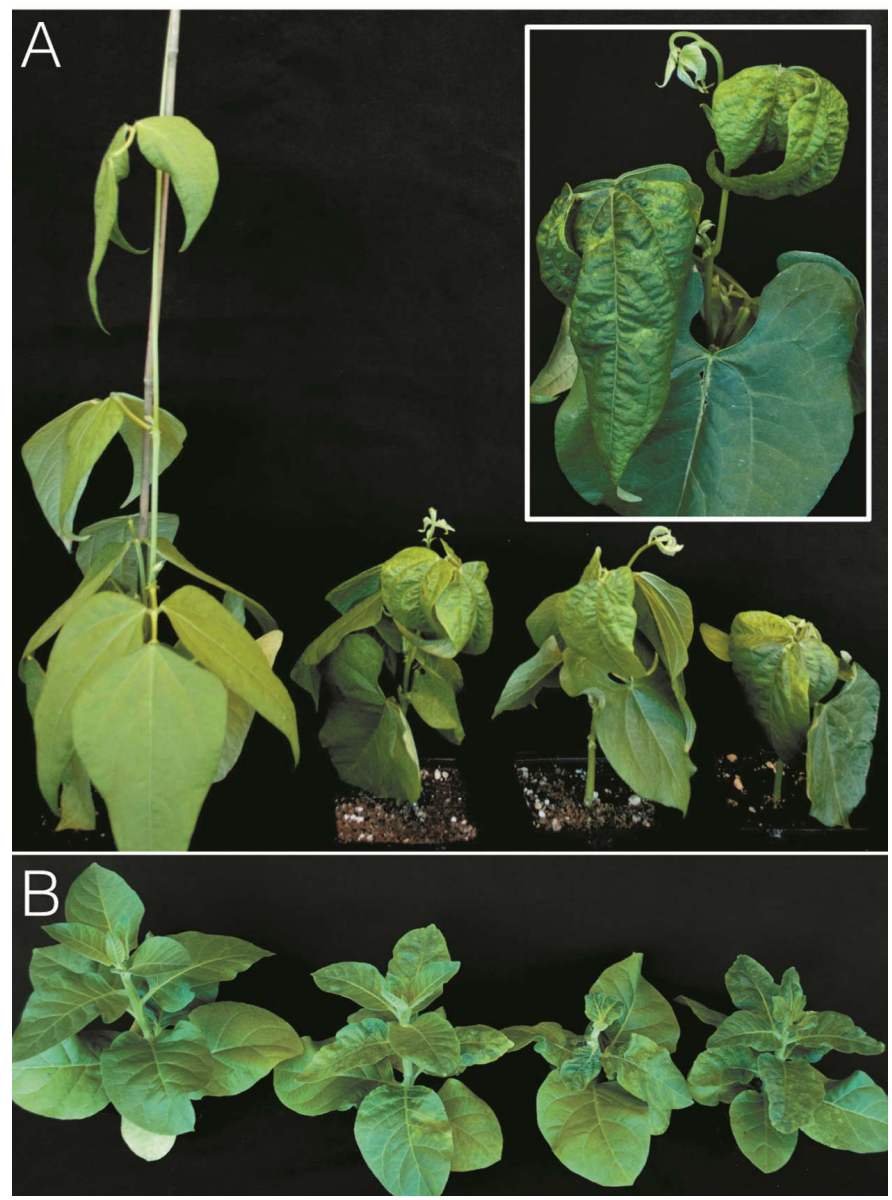

Fig. 5. Disease symptoms induced by cloned DNA-A and DNA-B components of Jatropha mosaic virus (JMV) strains from the Dominican Republic in common bean (Phaseolus vulgaris) and tobacco (Nicotiana tabacum) plants. From left to right are the empty-vector control and symptoms induced by JMV strains Az-4, Cl-10, and Ag-14, respectively, in A, 'Jacomelo' common bean and $\mathbf{B}$, 'Samsun' tobacco at 16 days after agroinoculation. The inset shows a close-up photograph of typical symptoms induced by JMV in common bean. iterons of the DNA-B components than for the IRDs of the Az-4 and Ag-14 strains. The IRD amino acid at positions $\mathrm{X}_{-2}, \mathrm{X}_{1}$, and $\mathrm{X}_{3}$ correspond to the amino acid 5, 8, and 10 of Rep and form the small sheet element $\beta 1$ which, together with amino acid 69 and 71 , form the $\beta 1 / \beta 5$ sheet element responsible for the interaction with the iterons $(3,22,80)$. The amino acid 69 and 71 of the Rep protein are identical in the three JMV strains, which lends further support to the notion that biological differences in the PRs might be explained by differences in the IRDs. Taken together, the asymmetry in the infectivity and replication properties of the PRs is consistent with the substantial genetic diversity among the JMV isolates from the DO and their designation as strains.
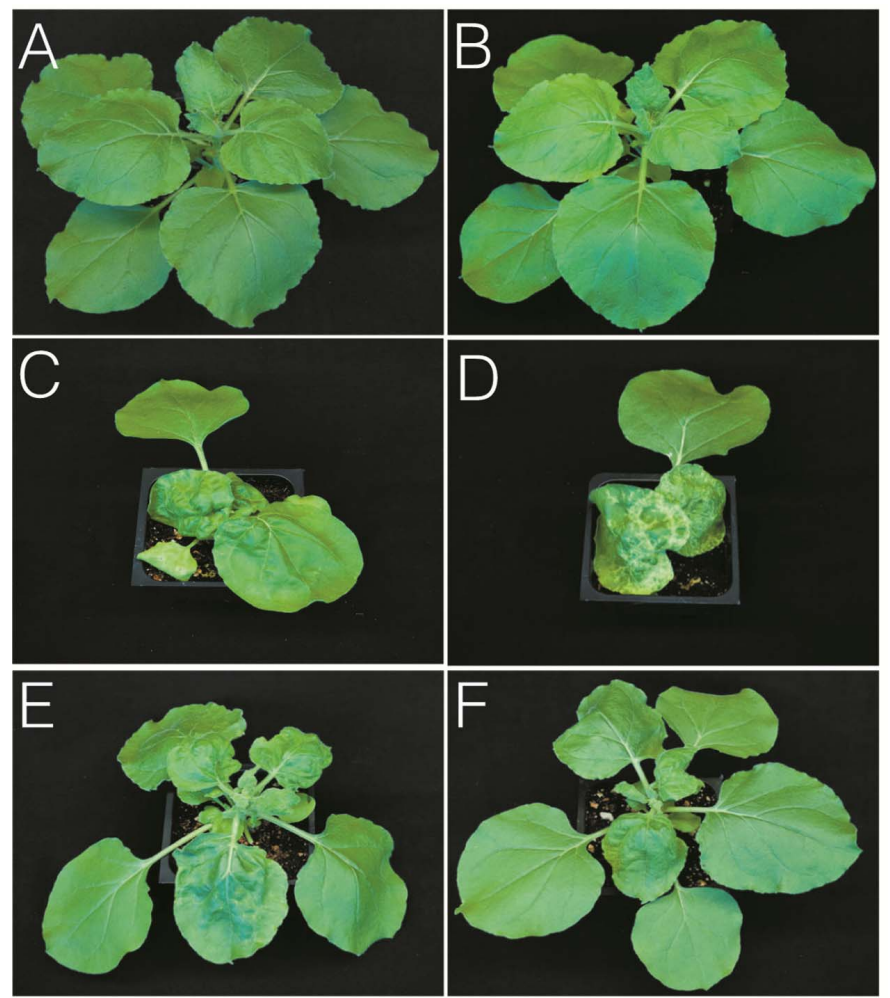

G

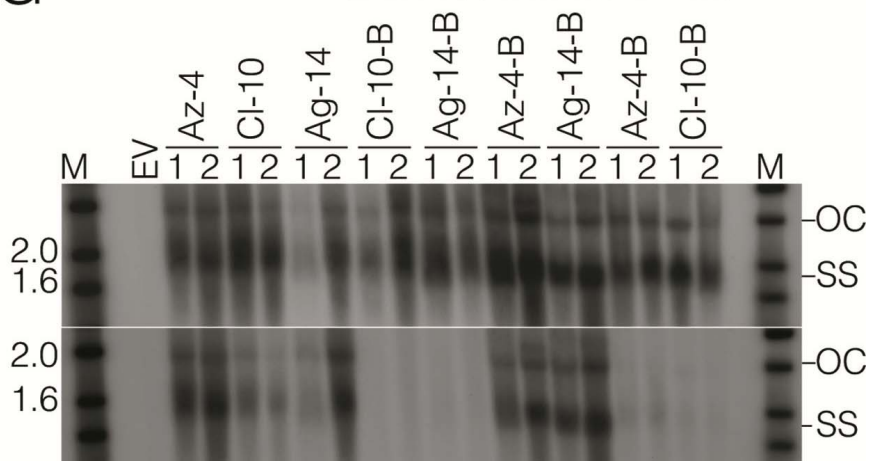

Fig. 6. Disease symptoms induced by the pseudorecombinants (PRs) generated with the infectious cloned DNA-A and DNA-B components of three strains of Jatropha mosaic virus (JMV) from the Dominican Republic (Az-4, Cl-10, and Ag-14) in Nicotiana benthamiana plants 14 days after agroinoculation. Symptoms induced by the following PRs: A, Az-4-A/Cl-10-B; B, Az-4-A/Ag-14-B; C, Cl-10-A/Az-4-B; D, Cl-10-A/Ag-14-B; E, Ag-14-A/Az4-B; and F, Ag-14-A/Cl-10-B. G, Southern blot hybridization analysis showing DNA replication levels of the cognate DNA-A and DNA-B components of these JMV strains and components of the PRs in $N$. benthamiana leaves 4 days after agroinfiltration. Blots in the upper and lower panels were hybridized with a DNA-A and DNA-B probe, respectively. Lane M, size marker (kb); lane EV, empty vector; and lanes 1 and 2 represent two different plants for each JMV strain or PR. Open circular (OC) double-stranded and singlestranded (SS) DNA forms are indicated. 


\section{DISCUSSION}

Noncultivated plants, including a wide variety of weeds, are commonly infected by begomoviruses in tropical and subtropical regions, where they often show striking golden or yellow mosaic symptoms but relatively little stunting or leaf curling and distortion. It has long been speculated that such weeds serve as reservoirs for crop-infecting begomoviruses. However, in most cases examined to date, these weeds have been infected by viruses that are genetically distinct from the prevalent crop-infecting viruses $(11,68,79)$. Furthermore, the fact that symptoms in weeds are often relatively mild (i.e., lacking severe stunting and leaf deformation) is suggestive of co-evolution of the virus and host. Thus, a more likely scenario, and one that has gained support from recent studies of begomovirus diversity in noncultivated plants $(11,68,79)$, is that weeds serve as sources of begomovirus genetic diversity and perhaps as mixing vessels for the emergence and evolution of crop-infecting begomoviruses. Moreover, once introduced into a crop host, subsequent evolution, via mutation and perhaps recombination, leads to considerable divergence from the original weed-infecting progenitor.

Here, we determined the etiology of the striking yellow mosaic disease in Jatropha spp. in the DO. A distinct bipartite begomovirus was associated with these symptoms in jatropha in Jamaica, and was named JMV (72). We confirmed and extended these results by showing that jatropha plants with yellow mosaic symptoms in the DO are infected by a complex of genetically distinct strains of JMV. Furthermore, we fulfilled Koch's postulates for this disease by establishing that the cloned DNA components of the JMV strains from the DO induce yellow mosaic symptoms in jatropha.

Given the genetic diversity of begomovirus DNA components that are often found in weeds, it is important to establish causality of the disease with cloned DNA components to definitively characterize these begomoviruses and the disease symptoms they induce in weed and crop hosts. For the strains of JMV characterized in the present study, agroinoculation was used to establish that the cloned DNA components were infectious in N. benthamiana, tobacco, and common bean; however, this method was not successful for establishing infectivity in jatropha. This was likely due to incompatibility of A. tumefaciens with jatropha, and is another example of the limitations of agroinoculation for delivering infectious clones of geminiviruses to certain hosts $(46,74)$. The importance of using multiple methods of inoculation was demonstrated by the fact that particle bombardment was successfully used to establish infectivity of the cloned DNA components of the JMV strains in jatropha. Furthermore, the development of yellow mosaic symptoms, indistinguishable from those observed in the field, in jatropha plants inoculated with the cloned DNA-A and DNA-B components of the JMV strains from the DO confirmed that JMV is the causal agent of this disease (i.e., fulfilled Koch's postulates). Finally, the capacity of JMV to be sap transmissible is consistent with the yellow mosaic symptom phenotype and may indicate that the virus is not phloemlimited, at least in some hosts. Indeed, this biological property was host dependent, being highly efficient for $N$. benthamiana but inefficient in other hosts.

Evidence that the jatropha begomovirus isolates from the DO were strains of JMV came from the results of the SDT analysis, indicating that the complete DNA-A sequence identities with the previously characterized JMV isolate from Jamaica were 90.6 to $92.3 \%$. This result supported the designation of the isolates from the DO as strains of JMV rather than distinct species. Sequence comparisons performed with individual genes further revealed that the Ag-2 isolate from Aguacatico is a variant of the Az-4 strain from Azua. Therefore, the JMV isolates from the DO are named JMV Az-4 strain [DO:Azua:2012], Ag-2 variant [DO:Aguacatico:2013], JMV Cl-10 strain [DO:Clavellina:2010], and JMV Ag-14 strain [DO:Aguacatico:2010].

Sequence comparisons with previously characterized begomoviruses revealed that the JMV variants or strains were most closely related to crop- and weed-infecting bipartite begomoviruses from the Caribbean Basin, particularly TbMoLCV and TbLCuCV from Cuba and WGMV from Jamaica. This finding is fully consistent with JMV representing a distinct NW bipartite begomovirus species that originated and evolved in the Caribbean Basin. Furthermore, the high level of genetic diversity found among the JMV strains from the DO and the isolate from Jamaica can be attributed to a relatively long period of geographic isolation, together with recombination and the high mutation rate of geminiviruses (16). This is supported by the finding of recombination in the genome of the JMV Cl-10 strain, and the high degree of sequence divergence in the $\mathrm{CR}$ and the $\mathrm{AC} 1, \mathrm{AC} 4$, and BV1 genes. The finding that PRs formed among JMV strains from the DO were asymmetric in terms of infectivity and symptomatology provided further evidence of local evolution and additional support for the strain designation.

The different biological properties of the PRs formed between the JMV strains reflected differences in DNA replication properties and genetic diversity in elements involved in DNA replication (i.e., Rep binding sites in the CR and the IRD motif in the $\mathrm{N}$ terminus of the Rep protein). The leaf disk replication assay,

TABLE 3. Nucleotide identities for common region (CR) sequences and infectivity of pseudorecombinants (PRs) generated between the cloned DNA-A and DNA-B components of three strains of Jatropha mosaic virus (JMV) from the Dominican Republic following agroinoculation

\begin{tabular}{|c|c|c|c|c|c|c|c|}
\hline \multirow[b]{3}{*}{$\mathrm{PRs}^{\mathrm{a}}$} & \multirow[b]{3}{*}{ CR identity (\%) } & \multirow{2}{*}{\multicolumn{2}{|c|}{ Symptomatology ${ }^{\mathrm{b}}$}} & \multicolumn{4}{|c|}{ Infectivity $^{c}$} \\
\hline & & & & \multicolumn{2}{|c|}{ Nicotiana benthamiana } & \multicolumn{2}{|c|}{ Common bean } \\
\hline & & $N$. benthamiana & Common bean & DNA-A & DNA-B & DNA-A & DNA-B \\
\hline Cl-10-B & 92 & $0 / 29^{\mathrm{NS}}$ & $0 / 18^{\mathrm{NS}}$ & $10 / 10$ & $0 / 10$ & $0 / 12$ & $0 / 12$ \\
\hline Ag-14-B & 87 & $0 / 29^{N S}$ & $0 / 18^{\mathrm{NS}}$ & $10 / 10$ & $0 / 10$ & $0 / 12$ & $0 / 12$ \\
\hline \multicolumn{8}{|l|}{$\mathrm{Cl}-10-\mathrm{A}$} \\
\hline Az-4-B & 90 & $29 / 29 * * *$ & $0 / 16^{\mathrm{NS}}$ & $12 / 12$ & $12 / 12$ & $6 / 10$ & $0 / 10$ \\
\hline Az-4-B & 87 & $29 / 29 *$ & $0 / 17^{\mathrm{NS}}$ & $15 / 15$ & $15 / 15$ & $9 / 10$ & $0 / 10$ \\
\hline Cl-10-B & 88 & $40 / 40 *$ & $0 / 17^{\mathrm{NS}}$ & $12 / 12$ & $12 / 12$ & $8 / 10$ & $0 / 10$ \\
\hline
\end{tabular}

a PRs were generated with the infectious cloned DNA-A and DNA-B components of three strains of JMV from the DO: Az-4, Cl-10, and Ag-14.

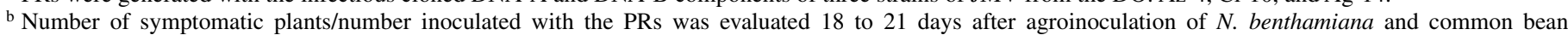
('Jacomelo') plants. Symptom development was evaluated based on the following rating scale: NS = no symptoms, $*=$ mild symptoms, $* *=$ moderate symptoms, and $* * *=$ severe symptoms. Results represent data from three independent experiments.

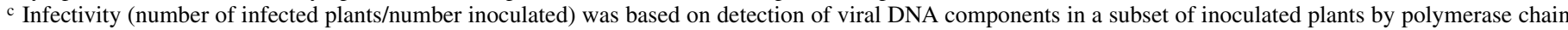
reaction (number of plants in which DNA component was detected/number inoculated) with strain-specific (DNA-A) and degenerate (DNA-B) primer pairs 18 to 21 days postinoculation. 
which allows for an assessment of the relative rates of DNA replication, independent of movement, revealed no or low levels of DNA-B component replication for PRs that were not infectious or poorly infectious. This is fully consistent with the need for the DNA-B-encoded MP and NSP proteins for cell-to-cell and longdistance movement $(23,70)$. Furthermore, the lack or low level of transreplication of the DNA-B component was associated with divergence in iteron sequences and variation in the IRD $(3,22$, $52,80)$. However, direct evidence for the role of these elements in replication must come from mutational analyses of infectious clones. The differences in DNA-A-alone infections for these PRs in common bean also indicate a possible contribution by other DNA-A-encoded factors (64). However, differences in the DNAA components do not explain the differential infectivity of the Cl-10-A/Az-4-B and Cl-10-A/Ag-14-B PRs. Both of these PRs infected and caused severe symptoms in $N$. benthamiana but only the Cl-10-A/Ag-14-B PR infected and caused severe symptoms in common bean. This may be due to differences in expression or function of DNA-B-encoded MPs, something that has been previously observed for PRs generated between Mungbean yellow mosaic India virus isolates (82) and Bean dwarf mosaic virus (BDMV) and Tomato mottle virus (40).

Our results provided evidence that jatropha infected with JMV strains in the DO may be both a source of genetic diversity for evolution of a crop-infecting begomoviruses as well as a potential reservoir for crop-infecting begomoviruses. Evidence that a JMV strain may have served as a progenitor for a crop-infecting begomovirus came from the finding that the most closely related begomoviruses were the tobacco-infecting TbMoLCV and TbLCuCV from Cuba (14,57). These tobacco-infecting begomoviruses could have evolved from a JMV progenitor that was introduced into tobacco by whiteflies and subsequently underwent divergence in the tobacco host. This hypothesis also gains support from the finding that the JMV strains were infectious and induced disease symptoms in tobacco.

The finding that the JMV strains infected plants species outside of the family of the natural host jatropha (Euphorbiaceae), including the solanaceous hosts $N$. benthamiana and tobacco, and common bean, raises the possibility that JMV can be a cropinfecting begomovirus in the DO with the potential to cause disease in these crops. The differential pathogenicity found for JMV in common bean, in which only some large-seeded Andean genotypes were infected, is similar to that shown by other bipartite begomoviruses, including BDMV and Cucurbit leaf crumple virus $(32,78,86)$. This reflects the overall higher level of resistance to begomovirus infection in the Middle American germplasm $(26,32,56)$. However, the fact that the Andean cultivar Jacomelo, which is grown commercially in the DO, was susceptible to JMV and developed severe disease symptoms indicates the potential for JMV to be a constraint on bean production in the DO. However, despite the fact that JMV can infect common bean and tobacco under experimental conditions, JMV infections of these crops in the DO have not been reported. It is possible that symptoms of stunting, leaf crumpling, and epinasty caused by JMV infection in these crops are not common or, in the case of common bean, are obscured by the symptoms induced by BGYMV. Another possibility is that vector specificity may limit JMV to jatropha. In this regard, a "jatropha race" of B. tabaci has been described from Puerto Rico, which is a monophagus variant of B. tabaci that colonizes J. gossypifolia plants (8). If a similar situation exists in the DO, it might explain why JMV has not been detected infecting bean and tobacco.

In conclusion, we have established that jatropha yellow mosaic disease in the DO is caused by a complex of genetically divergent strains of JMV. In addition to jatropha, these JMV strains also can infect and cause severe symptoms in common bean and tobacco plants, revealing the potential for this weed-infecting begomovirus to either serve as a progenitor for crop-infecting begomo- viruses or itself infect and cause disease in crop plants. Finally, the high level of sequence divergence in the JMV strains and the asymmetry in the PRs formed between the DNA components of these strains is suggestive of a long period of local evolution in geographically isolated populations.

\section{ACKNOWLEDGMENTS}

This research was supported, in part, by the Integrated Pest Management-Collaborative Research Support Program (IPM-CRSP). This project was made possible by the United States Agency for International Development (USAID) and the generous support of the American people through the USAID Cooperative Agreement Number EPPA-00-04-0001600 . We thank the Ministry of Agriculture of the DO for its support; A. Almanzar of Transagricola S. A. (Av. Duarte 269 Navarette, Santiago, DO Apartado 713) for cooperation in collecting the disease samples used in this study and for providing seed of common bean cultivars commercially grown in the DO; and D. Parfitt of the Department of Plant Science at UC Davis and M. Pastor-Corrales of the United States Department of Agriculture-Agricultural Research Service at Beltsville, MD for providing jatropha and common bean seed, respectively.

\section{LITERATURE CITED}

1. Achten, W. M. J., Verchot, L., Franken, Y. J., Mathijs, E., Singh, V. P., Aerts, R., and Muys, B. 2008. Jatropha bio-diesel production and use. Biomass Bioener. 32:1063-1084.

2. Alabi, O. J., Ogbe, F. O., Bandyopadhyay, R., Kumar, P. L., Dixon, A. G., Hughes, J. d. A., and Naidu, R. A. 2008. Alternate hosts of African cassava mosaic virus and East African cassava mosaic Cameroon virus in Nigeria. Arch. Virol. 153:1743-1747.

3. Argüello-Astorga, G. R., and Ruiz-Medrano, R. 2001. An iteron-related domain is associated to Motif 1 in the replication proteins of geminiviruses: Identification of potential interacting amino acid-base pairs by a comparative approach. Arch. Virol. 146:1465-1485.

4. Barbosa, J. C., Barreto, S. S., Inoue-Nagata, A. K., Reis, M. S., Firmino, A. C., Bergamin-Filho, A., and Rezende, J. A. M. 2009. Natural infection of Nicandra physaloides by Tomato severe rugose virus in Brazil. J. Gen. Plant Pathol. 75:440-443.

5. Barreto, S. S., Hallwass, M., Aquino, O. M., and Inoue-Nagata, A. K. 2013. A study of weeds as potential inoculum sources for a tomatoinfecting begomovirus in Central Brazil. Phytopathology 103:436-444.

6. Borders, C. L., Broadwater, J. A., Bekeny, P. A., Salmon, J. E., Lee, A. S., Eldridge, A. M., and Pett, V. B. 1994. A structural role for arginine in proteins: Multiple hydrogen bonds to backbone carbonyl oxygens. Protein Sci. 3:541-548.

7. Briddon, R. W., Patil, B. L., Bagewadi, B., Nawaz-ul-Rehman, M. S., and Fauquet, C. M. 2010. Distinct evolutionary histories of the DNA-A and DNA-B components of bipartite begomoviruses. BMC Evol. Biol. 10:97. doi:10.1186/1471-2148-10-97

8. Brown, J. K., and Bird, J. 1992. Whitefly-transmitted geminiviruses and associated disorders in the Americas and the Caribbean Basin. Plant Dis. 76:220-225

9. Bryant, D., and Moulton, V. 2004. Neighbor-net: An agglomerative method for the construction of phylogenetic networks. Mol. Biol. Evol. 21:255-265.

10. Bull, S. E., Briddon, R. W., Sserubombwe, W. S., Ngugi, K., Markham, P. G., and Stanley, J. 2007. Infectivity, pseudorecombination and mutagenesis of Kenyan cassava mosaic begomoviruses. J. Gen. Virol. 88:16241633.

11. Castillo-Urquiza, G. P., Beserra, J. E. A., Jr., Bruckner, F. P., Lima, A. T., Varsani, A., Alfenas-Zerbini, P., and Zerbini, F. M. 2008. Six novel begomoviruses infecting tomato and associated weeds in southeastern Brazil. Arch. Virol. 153:1985-1989.

12. Chakraborty, S., Vanitharani, R., Chattopadhyay, B., and Fauquet, C. M. 2008. Supervirulent pseudorecombination and asymmetric synergism between genomic components of two distinct species of begomovirus associated with severe tomato leaf curl disease in India. J. Gen. Virol. 89:818-828.

13. Dellaporta, S. L., Wood, J., and Hicks, J. B. 1983. A plant DNA minipreparation: Version II. Plant Mol. Biol. Rep. 1:19-21.

14. Domínguez, M., Ramos, P. L., Sánchez, Y., Crespo, J., Andino, V., Pujol, M., and Borroto, C. 2009. Tobacco mottle leaf curl virus, a new begomovirus infecting tobacco in Cuba. Plant Pathol. 58:786.

15. Donald, J. E., Kulp, D. W., and DeGrado, W. F. 2011. Salt bridges: Geometrically specific, designable interactions. Proteins 79:898-915.

16. Duffy, S., Shackelton, L. A., and Holmes, E. C. 2008. Rates of 
evolutionary change in viruses: Patterns and determinants. Nat. Rev. Genet. 9:267-276.

17. Faria, J. C. D., Gilbertson, R. L., Hanson, S. F., Morales, F. J., Ahlquist, P., Loniello, A. O., and Maxwell, D. P. 1994. Bean golden mosaic geminivirus type II isolates from the Dominican Republic and Guatemala: Nucleotide sequences, infectious pseudorecombinants, and phylogenetic relationships. Phytopathology 84:321-329.

18. Fauquet, C. M., Briddon, R. W., Brown, J. K., Moriones, E., Stanley, J., Zerbini, F. M., and Zhou, X. 2008. Geminivirus strain demarcation and nomenclature. Arch. Virol. 153:783-821.

19. Fiallo-Olivé, E., Navas-Castillo, J., Moriones, E., and Martínez-Zubiaur, Y. 2010. Two novel begomoviruses belonging to different lineages infecting Rhynchosia minima. Arch. Virol. 155:2053-2058.

20. Fiallo-Olivé, E., Navas-Castillo, J., Moriones, E., and Martínez-Zubiaur, Y. 2012. Begomoviruses infecting weeds in Cuba: Increased host range and a novel virus infecting Sida rhombifolia. Arch. Virol. 157:141-146.

21. Fiallo-Olivé, E., Rivera-Bustamante, R. F., and Martínez-Zubiaur, Y. 2009. Tobacco yellow crinkle virus, a new bipartite begomovirus infecting tobacco and pepper in Cuba. Plant Pathol. 58:785.

22. Fontes, E. P., Gladfelter, H. J., Schaffer, R. L., Petty, I. T., and HanleyBowdoin, L. 1994. Geminivirus replication origins have a modular organization. Plant Cell 6:405-416.

23. Frischmuth, T., Roberts, S., von Arnim, A., and Stanley, J. 1993. Specificity of bipartite geminivirus movement proteins. Virology 196:666-673.

24. Gao, S., Qu, J., Chua, N. H., and Ye, J. 2010. A new strain of Indian cassava mosaic virus causes a mosaic disease in the biodiesel crop Jatropha curcas. Arch. Virol. 155:607-612.

25. García-Andrés, S., Monci, F., Navas-Castillo, J., and Moriones, E. 2006. Begomovirus genetic diversity in the native plant reservoir Solanum nigrum: Evidence for the presence of a new virus species of recombinant nature. Virology 350:433-442.

26. Garrido-Ramirez, E. R., Sudarshana, M. R., and Gilbertson, R. L. 2000. Bean golden yellow mosaic virus from Chiapas, Mexico: Characterization, pseudorecombination with other bean-infecting geminiviruses and germ plasm screening. Phytopathology 90:1224-1232.

27. Gilbertson, R. L., Faria, J. C., Ahlquist, P., and Maxwell, D. P. 1993. Genetic diversity in geminiviruses causing bean golden mosaic disease: The nucleotide sequence of the infectious cloned DNA components of a Brazilian isolate of bean golden mosaic geminivirus. Phytopathology 83:709-715.

28. Gilbertson, R. L., Faria, J. C., Hanson, S. F., Morales, F. J., Ahlquist, P. G., Maxwell, D. P., and Russell, D. R. 1991. Cloning of the complete DNA genomes of four bean-infecting geminiviruses and determining their infectivity by electric discharge particle acceleration. Phytopathology 81:980-985.

29. Gilbertson, R. L., Hidayat, S. H., Martinez, R. T., Leong, S. A., Faria, J. C., Morales, F., and Maxwell, D. P. 1991. Differentiation of beaninfecting geminiviruses by nucleic acid hybridization probes and aspects of bean golden mosaic in Brazil. Plant Dis. 75:336-342.

30. Gilbertson, R. L., Hidayat, S. H., Paplomatas, E. J., Rojas, M. R., Hou, Y. M., and Maxwell, D. P. 1993. Pseudorecombination between infectious cloned DNA components of tomato mottle and bean dwarf mosaic geminiviruses. J. Gen. Virol. 74:23-31.

31. Gutierrez, C. 1999. Geminivirus DNA replication. Cell. Mol. Life Sci. 56:313-329.

32. Hagen, C., Rojas, M. R., Sudarshana, M. R., Xoconostle-Cazares, B., Natwick, E. T., Turini, T. A., and Gilbertson, R. L. 2008. Biology and molecular characterization of Cucurbit leaf crumple virus, an emergent cucurbit-infecting begomovirus in the Imperial Valley of California. Plant Dis. 92:781-793.

33. Hajdukiewicz, P., Svab, Z., and Maliga, P. 1994. The small, versatile pPZP family of Agrobacterium binary vectors for plant transformation. Plant Mol. Biol. 25:989-994.

34. Hanley-Bowdoin, L., Bejarano, E. R., Robertson, D., and Mansoor, S. 2013. Geminiviruses: Masters at redirecting and reprogramming plant processes. Nat. Rev. Microbiol. 11:777-788.

35. Hanley-Bowdoin, L., Settlage, S. B., Orozco, B. M., Nagar, S., and Robertson, D. 1999. Geminiviruses: Models for plant DNA replication, transcription, and cell cycle regulation. Crit. Rev. Plant Sci. 18:71-106.

36. Harrison, B. D., Swanson, M. M., and Fargette, D. 2002. Begomovirus coat protein: Serology, variation and functions. Physiol. Mol. Plant Pathol. 60:257-271.

37. Hill, J. E., Strandberg, J. O., Hiebert, E., and Lazarowitz, S. G. 1998. Asymmetric infectivity of pseudorecombinants of cabbage leaf curl virus and squash leaf curl virus: Implications for bipartite geminivirus evolution and movement. Virology 250:283-292.

38. Höfer, P., Engel, M., Jeske, H., and Frischmuth, T. 1997. Host range limitation of a pseudorecombinant virus produced by two distinct bipartite geminiviruses. Mol. Plant-Microbe Interact. 10:1019-1022.
39. Hou, Y. M., and Gilbertson, R. L. 1996. Increased pathogenicity in a pseudorecombinant bipartite geminivirus correlates with intermolecular recombination. J. Virol. 70:5430-5436.

40. Hou, Y. M., Paplomatas, E. J., and Gilbertson, R. L. 1998. Host adaptation and replication properties of two bipartite geminiviruses and their pseudorecombinants. Mol. Plant-Microbe Interact. 11:208-217.

41. Huson, D. H., and Bryant, D. 2006. Application of phylogenetic networks in evolutionary studies. Mol. Biol. Evol. 23:254-267.

42. Idris, A. M., Mills-Lujan, K., Martin, K., and Brown, J. K. 2008. Melon chlorotic leaf curl virus: Characterization and differential reassortment with closest relatives reveal adaptive virulence in the Squash leaf curl virus clade and host shifting by the host-restricted Bean calico mosaic virus. J. Virol. 82:1959-1967.

43. Inoue-Nagata, A. K., Albuquerque, L. C., Rocha, W. B., and Nagata, T. 2004. A simple method for cloning the complete begomovirus genome using the bacteriophage phi29 DNA polymerase. J. Virol. Methods 116:209-211.

44. Jovel, J., Reski, G., Rothenstein, D., Ringel, M., Frischmuth, T., and Jeske, H. 2004. Sida micrantha mosaic is associated with a complex infection of begomoviruses different from Abutilon mosaic virus. Arch. Virol. 149:829-841.

45. Kashina, B. D., Alegbejo, M. D., Banwo, O. O., Nielsen, S. L., and Nicolaisen, M. 2013. Molecular identification of a new begomovirus associated with mosaic disease of Jatropha curcas L. in Nigeria. Arch. Virol. 158:511-514.

46. Kon, T., Rojas, M. R., Abdourhamane, I. K., and Gilbertson, R. L. 2009. Roles and interactions of begomoviruses and satellite DNAs associated with okra leaf curl disease in Mali, West Africa. J. Gen. Virol. 90:10011013.

47. Lefeuvre, P., Lett, J. M., Varsani, A., and Martin, D. 2009. Widely conserved recombination patterns among single-stranded DNA viruses. J. Virol. 83:2697-2707.

48. Lefeuvre, P., Martin, D. P., Harkins, G., Lemey, P., Gray, A. J. A., Meredith, S., Lakay, F., Monjane, A., Lett, J. M., and Varsani, A. 2010. The spread of Tomato yellow leaf curl virus from the Middle East to the world. PLoS Pathog. 6:e10.1371/journal.ppat.1001164

49. Lima, A. T., Sobrinho, R. R., González-Aguilera, J., Rocha, C. S., Silva, S. J., Xavier, C. A., Silva, F. N., Duffy, S., and Zerbini, F. M. 2013. Synonymous site variation due to recombination explains higher genetic variability in begomovirus populations infecting non-cultivated hosts. J. Gen. Virol. 94:418-431.

50. Lole, K. S., Bollinger, R. C., Paranjape, R. S., Gadkari, D., Kulkarni, S. S., Novak, N. G., Ingersoll, R., Sheppard, H. W., and Ray, S. C. 1999. Full-length human immunodeficiency virus type 1 genomes from subtype C-infected seroconverters in India, with evidence of intersubtype recombination. J. Virol. 73:152-160.

51. Martin, D. P. 2009. Recombination detection and analysis using RDP3. Methods Mol. Biol. 537:185-205.

52. Mauricio-Castillo, J. A., Torres-Herrera, S. I., Cárdenas-Conejo, Y., Pastor-Palacios, G., Méndez-Lozano, J., and Argüello-Astorga, G. R. 2014. A novel begomovirus isolated from sida contains putative cis-and trans-acting replication specificity determinants that have evolved independently in several geographical lineages. Arch. Virol. 159:22832294.

53. Melgarejo, T. A., Kon, T., Rojas, M. R., Paz-Carrasco, L., Zerbini, F. M., and Gilbertson, R. L. 2013. Characterization of a New World monopartite begomovirus causing leaf curl disease of tomato in Ecuador and Peru reveals a new direction in geminivirus evolution. J. Virol. 87:5397-5413.

54. Monde, G., Walangululu, J., Winter, S., and Bragard, C. 2010. Dual infection by cassava begomoviruses in two leguminous species (Fabaceae) in Yangambi, Northeastern Democratic Republic of Congo. Arch. Virol. 155:1865-1869.

55. Morales, F. J., and Anderson, P. K. 2001. The emergence and dissemination of whitefly-transmitted geminiviruses in Latin America. Arch. Virol. 146:415-441.

56. Morales, F. J., and Singh, S. P. 1993. Breeding for resistance to bean golden mosaic virus in an interracial population of Phaseolus vulgaris $\mathrm{L}$. Euphytica 67:59-63.

57. Morán, Y. M., Ramos, P. L., Domínguez, M., Fuentes, A. D., Sánchez, Y., and Crespo, J. A. 2006. Tobacco leaf curl Cuba virus, a new begomovirus infecting tobacco (Nicotiana tabacum) in Cuba. Plant Pathol. 55:570

58. Mubin, M., Shahid, M. S., Tahir, M. N., Briddon, R. W., and Mansoor, S. 2010. Characterization of begomovirus components from a weed suggests that begomoviruses may associate with multiple distinct DNA satellites. Virus Genes 40:452-457.

59. Muhire, B., Martin, D. P., Brown, J. K., Navas-Castillo, J., Moriones, E., Zerbini, F. M., Rivera-Bustamante, R., Malathi, V. G., Briddon, R. W., and Varsani, A. 2013. A genome-wide pairwise-identity-based proposal for the classification of viruses in the genus Mastrevirus (family Geminiviridae). Arch. Virol. 158:1411-1424. 
60. Narayana, D. S. A., Rangaswamy, K. T., Shankarappa, K. S., Maruthi, M. N., Reddy, C. N. L., Rekha, A. R., and Murthy, K. V. K. 2007. Distinct begomoviruses closely related to cassava mosaic viruses cause Indian jatropha mosaic disease. Int. J. Virol. 3:1-11.

61. Padidam, M., Sawyer, S., and Fauquet, C. M. 1999. Possible emergence of new geminiviruses by frequent recombination. Virology 265:218-225.

62. Page, R. D. M. 1996. TreeView: An application to display phylogenetic trees on personal computers. Comput. Appl. Biosci. 12:357-358.

63. Paplomatas, E. J., Patel, V. P., Hou, Y.-M., Noueiry, A., and Gilbertson, R. L. 1994. Molecular characterization of a new sap-transmissible bipartite genome geminivirus infecting tomatoes in Mexico. Phytopathology 84:1215-1223.

64. Petty, I. T., Carter, S. C., Morra, M. R., Jeffrey, J. L., and Olivey, H. E. 2000. Bipartite geminivirus host adaptation determined cooperatively by coding and noncoding sequences of the genome. Virology 277:429-438.

65. Posada, D. 2008. jModelTest: Phylogenetic model averaging. Mol. Biol. Evol. 25:1253-1256.

66. Radford, S. E. 2000. Protein folding: Progress made and promises ahead. Trends Biochem. Sci. 25:611-618.

67. Ramos, P. L., Guevara-Gonzalez, R. G., Peral, R., Ascencio-Ibanez, J. T., Polston, J. E., Argüello-Astorga, G. R., Vega-Arreguin, J. C., and RiveraBustamante, R. F. 2003. Tomato mottle Taino virus pseudorecombines with PYMV but not with ToMoV: Implications for the delimitation of cisand trans-acting replication specificity determinants. Arch. Virol. 148: 1697-1712.

68. Rocha, C. S., Castillo-Urquiza, G. P., Lima, A. T., Silva, F. N., Xavier, C. A., Hora-Júnior, B. T., Beserra-Júnior, J. E., Malta, A. W., Martin, D. P., Varsani, A., Alfenas-Zerbini, P., Mizubuti, E. S., and Zerbini, F. M. 2013. Brazilian begomovirus populations are highly recombinant, rapidly evolving, and segregated based on geographical location. J. Virol. $87: 5784-5799$

69. Rojas, M. R., Gilbertson, R. L., Russell, D. R., and Maxwell, D. P. 1993. Use of degenerate primers in the polymerase chain reaction to detect whitefly-transmitted geminiviruses. Plant Dis. 77:340-347.

70. Rojas, M. R., Hagen, C., Lucas, W. J., and Gilbertson, R. L. 2005. Exploiting chinks in the plant's armor: Evolution and emergence of geminiviruses. Annu. Rev. Phytopathol. 43:361-394.

71. Ronquist, F., Teslenko, M., van der Mark, P., Ayres, D. L., Darling, A., Höhna, S., Larget, B., Liu, L., Suchard, M. A., and Huelsenbeck, J. P. 2012. MrBayes 3.2: Efficient Bayesian phylogenetic inference and model choice across a large model space. Syst. Biol. 61:539-542.

72. Roye, M., Collins, A., and Maxwell, D. 2006. First report of a begomovirus associated with the common weed Jatropha gossypifolia in Jamaica. Plant Pathol. 55:286.

73. Roye, M. E., McLaughlin, W. A., Nakhla, M. K., and Maxwell, D. P. 1997. Genetic diversity among geminiviruses associated with the weed species Sida spp., Macroptilium lathyroides, and Wissadula amplissima from Jamaica. Plant Dis. 81:1251-1258.

74. Saeed, M. 2008. Limitations observed in the use of agroinoculation for geminivirus research. Virus Genes 37:434-435.
75. Salati, R., Nahkla, M. K., Rojas, M. R., Guzman, P., Jaquez, J., Maxwell, D. P., and Gilbertson, R. L. 2002. Tomato yellow leaf curl virus in the Dominican Republic: Characterization of an infectious clone, virus monitoring in whiteflies, and identification of reservoir hosts. Phytopathology 92:487-496.

76. Sánchez-Campos, S., Martínez-Ayala, A., Márquez-Martín, B., AragónCaballero, L., Navas-Castillo, J., and Moriones, E. 2013. Fulfilling Koch's postulates confirms the monopartite nature of tomato leaf deformation virus, a begomovirus native to the New World. Virus Res. 173:286-293.

77. Schmittgen, T. D., and Livak, K. J. 2008. Analyzing real-time PCR data by the comparative C(T) method. Nat. Protocols 3:1101-1108.

78. Seo, Y.-S., Gepts, P., and Gilbertson, R. 2004. Genetics of resistance to the geminivirus, Bean dwarf mosaic virus, and the role of the hypersensitive response in common bean. Theor. Appl. Genet. 108:786-793.

79. Silva, S. J. C., Castillo-Urquiza, G. P., Hora-Júnior, B. T., Assunção, I. P., Lima, G. S. A., Pio-Ribeiro, G., Mizubuti, E. S. G., and Zerbini, F. M. 2012. Species diversity, phylogeny and genetic variability of begomovirus populations infecting leguminous weeds in Northeastern Brazil. Plant Pathol. 61:457-467.

80. Singh, D. K., Malik, P. S., Choudhury, N. R., and Mukherjee, S. K. 2008. MYMIV replication initiator protein (Rep): Roles at the initiation and elongation steps of MYMIV DNA replication. Virology 380:75-83.

81. Stewart, C., Kon, T., Rojas, M., Graham, A., Martin, D., Gilbertson, R., and Roye, M. 2014. Mixed infection of Sida jamaicensis in Jamaica reveals the presence of three recombinant begomovirus DNA A components. Arch. Virol. 159:2509-2512.

82. Surendranath, B., Usharani, K. S., Nagma, A., Victoria, A. K., and Malathi, V. G. 2005. Absence of interaction of genomic components and complementation between Mungbean yellow mosaic India virus isolates in cowpea. Arch. Virol. 150:1833-1844.

83. Tamura, K., Peterson, D., Peterson, N., Stecher, G., Nei, M., and Kumar, S. 2011. MEGA5: Molecular evolutionary genetics analysis using maximum likelihood, evolutionary distance, and maximum parsimony methods. Mol. Biol. Evol. 28:2731-2739.

84. Umaharan, P., Padidam, M., Phelps, R. H., Beachy, R. N., and Fauquet, C. M. 1998. Distribution and diversity of geminiviruses in Trinidad and Tobago. Phytopathology 88:1262-1268.

85. Vaghchhipawala, Z., Rojas, C. M., Senthil-Kumar, M., and Mysore, K. S. 2011. Agroinoculation and agroinfiltration: Simple tools for complex gene function analyses. Pages 65-76 in: Plant Reverse Genetics: Methods and Protocols. A. Pereira, ed. Springer, Berlin.

86. Wang, H. L., Gilbertson, R. L., and Lucas, W. J. 1996. Spatial and temporal distribution of bean dwarf mosaic geminivirus in Phaseolus vulgaris and Nicotiana benthamiana. Phytopathology 86:1204-1214.

87. Wise, A. A., Liu, Z., and Binns, A. N. 2006. Three methods for the introduction of foreign DNA into Agrobacterium. Methods Mol. Biol. 343:43-53

88. Wyant, P. S., Gotthardt, D., Schäfer, B., Krenz, B., and Jeske, H. 2011. The genomes of four novel begomoviruses and a new Sida micrantha mosaic virus strain from Bolivian weeds. Arch. Virol. 156:347-352. 